OPEN ACCESS

Edited by:

Yu Guo,

The First Affiliated Hospital of Sun Yat-Sen University, China

Reviewed by:

Xiqiang Liu,

Southern Medical University, China

Yujie Liang,

Sun Yat-Sen University, China

*Correspondence:

Lili Chen

chenlili1030@hust.edu.cn

${ }^{\dagger}$ These authors have contributed equally to this work

Specialty section: This article was submitted to

Molecular Diagnostics and

Therapeutics,

a section of the journal

Frontiers in Molecular Biosciences

Received: 30 May 2021

Accepted: 23 July 2021

Published: 23 August 2021

Citation:

Sun J, Tang Q, Zhang J, Chen G, Peng $J$ and Chen L (2021) Possible Immunotherapeutic Strategies Based on Carcinogen-Dependent Subgroup

Classification for Oral Cancer.

Front. Mol. Biosci. 8:717038.

doi: $10.3389 /$ fmolb.2021.717038

\section{Possible Immunotherapeutic Strategies Based on Carcinogen-Dependent Subgroup Classification for Oral Cancer}

\author{
Jiwei Sun ${ }^{1,2,3 \dagger}$, Qingming Tang ${ }^{1,2,3 \dagger}$, Junyuan Zhang ${ }^{1,2,3}$, Guangjin Chen ${ }^{1,2,3}$, Jinfeng Peng ${ }^{1,2,3}$ \\ and Lili Chen ${ }^{1,2,3 *}$
}

${ }^{1}$ Department of Stomatology, Union Hospital, Tongji Medical College, Huazhong University of Science and Technology, Wuhan, China, ${ }^{2}$ School of Stomatology, Tongji Medical College, Huazhong University of Science and Technology, Wuhan, China, ${ }^{3}$ Hubei Province Key Laboratory of Oral and Maxillofacial Development and Regeneration, Wuhan, China

The oral cavity serves as an open local organ of the human body, exposed to multiple external factors from the outside environment. Coincidentally, initiation and development of oral cancer are attributed to many external factors, such as smoking and drinking, to a great extent. This phenomenon was partly explained by the genetic abnormalities traditionally induced by carcinogens. However, more and more attention has been attracted to the influence of carcinogens on the local immune status. On the other hand, immune heterogeneity of cancer patients is a huge obstacle for enhancing the clinical efficacy of tumor immunotherapy. Thus, in this review, we try to summarize the current opinions about variant genetic changes and multiple immune alterations induced by different oral cancer carcinogens and discuss the prospects of targeted immunotherapeutic strategies based on specific immune abnormalities caused by different carcinogens, as a predictive way to improve clinical outcomes of immunotherapy-treated oral cancer patients.

Keywords: immunotherapies, oral squamous cell carcinoma, immune microenvironment, smoking, areca nut

\section{INTRODUCTION}

Oral squamous cell carcinoma (OSCC) serves as one of the most important subtypes in head and neck squamous cell carcinoma (HNSCC), diagnosed cases of which have mounted to more than 600,000 worldwide, along with 50,000 new cases each year (Rahman et al., 2019). Unlike many other types of cancers whose pathogenesis is mainly explained by innate genetic alterations, OSCC is mainly related to some classical environmental risk factors such as tobacco and alcohol (Solomon et al., 2018). This phenomenon is easy to understand as the oral cavity is an open organ exposed to the outside environment and has broad interactions with environmental factors. On the other hand, with the development of oncogenic studies, the role of abnormality in the tumor microenvironment has been identified to be more and more important (Binnewies et al., 2018). Recently, many types of immune cells, such as M2 macrophages, regulatory T (Treg) cells, and myeloid-derived suppressor cells (MDSCs), were discovered to exert a pro-tumor influence on oral carcinogenesis (Dar et al., 2020; Li et al., 2020). The cell-cell communications mediated by extracellular vesicles have been identified as crucial mechanisms contributing to tumor progression in many types of carcinomas. Similarly, extracellular vesicles from multiple origins could get involved in many tumor-associated 
processes, including proliferation, metastasis, and drug resistance during oral cancer development (Xie et al., 2019). The above clues together indicated whether environmental risk factors could promote OSCC progress via deregulation of the tumor microenvironment. In the perspective of tumor therapy, immunotherapies, including check-point therapy and molecule-targeted strategy, have been making significant advances and improving the prognostic outcome of tumor patients to a great extent (Kennedy and Salama, 2020). However, immunotherapy has failed to be the prior strategy for OSCC treatment, partly due to the heterogeneity of OSCC patients, as multiple types of risk factors, for example, smoking and drinking, were involved in the initiation and progression of OSCC. Considering the fact that the huge financial burden and surgical complications are the main blockades for favorable clinical outcomes of OSCC patients, a therapeutic strategy based on patient-specific risk factors is extremely necessary to direct the application of different types of immunotherapies to different patients. This kind of strategy might overcome the heterogeneity of OSCC patients and realize individual-based diagnosis and therapy for OSCC patients, paving the way for the future of OSCC immune therapies.

\section{POSSIBLE CARCINOGENS FOR THE DEVELOPMENT OF OSCC}

Exogenous carcinogen-induced tumorigenesis acts as a significant feature of OSCC, distinguishing it from other cancers. Until now, multiple kinds of substances were regarded as possible OSCC carcinogens.

Among all the possible carcinogens for OSCC, cigarette, alcohol, and areca nuts were the most prevalent and wellacknowledged carcinogens (Kumar et al., 2016). Lots of clinical and epidemiological research has identified the strong relationship between smoking and OSCC. Results of a study based on 1,114 participants showed that the risk of OSCC among non-drinkers amounted to the quantity of smoking (Blot et al., 1988). In different regions, such as East Asia, Iran, and Brazil, OSCC patients all exhibited a high percentage of smoking habits, indicating a general influence of smoking on OSCC initiation (Razavi et al., 2015; Bezerra et al., 2018; Hashibe et al., 2019). Furthermore, OSCC patients with a smoking habit showed more aggressive disease features and poorer prognostic outcomes than non-smoking OSCC patients, indicating that smoking might also contribute to the progression and aggression of OSCC (Al Feghali et al., 2019). Alcohol abuse has been implicated as a high risk factor in many types of cancers, including OSCC (Ng et al., 1993), esophageal cancer (Castellsagué et al., 1999), larynx cancer (Bosetti et al., 2002), colorectal cancer (Cho et al., 2004), and pancreatic cancer (Korc et al., 2017). For OSCC, alcoholic beverages have been implicated as an important carcinogen in the etiology of oral cancer since the 1980s (Kabat and Wynder, 1989). Risk of OSCC among non-smokers was also confirmed to increase along with alcohol consumption (Blot et al., 1988). Specifically, a combination of alcohol abuse and smoking could enhance the carcinogenic effect of each other, suggesting a synergistic effect of alcoholism during OSCC development (Castellsagué et al., 2004). It is well known that the habit of chewing areca nuts is widely popular in Southeast Asia, and its positive role in the development of oral precancerous lesions and OSCC has been fully accepted as well (Li et al., 2016). As the areca nut industry was growing fast worldwide, more and more public and medical sources were paid due to betel chewing-induced OSCC (Hu et al., 2017).

Besides the above carcinogens, periodontal infection was also reported to be associated with OSCC development. Lower frequency of tooth-brushing and fewer dental visits, which were highly related with periodontal infection, were all associated with OSCC development. The poorer overall survival of OSCC patients with poor periodontal hygiene further suggested possible roles of periodontal infection in OSCC. With the development of society and subsequent changes in traditional concepts, the frequency of oral sexual behavior has mounted to a high level, especially in young adults (Holway and Hernandez, 2018). This behavior shift makes the oral cavity exposed to a totally new environment. Clinical trials have revealed that changes in sexual behaviors trend toward a higher incidence of oral human papillomavirus (HPV) infection (Chaturvedi et al., 2015). This phenomenon just coincides with the conclusion that the percentage of HPVpositive oropharyngeal carcinomas has risen from $16.3 \%$ in the 1980 s to $72.7 \%$ in the 2000 s (Chow, 2020). Obviously, oral sex-mediated HPV exposure has become a newly emerging risk factor for oral and pharyngeal carcinomas.

In addition, some novel perspectives about OSCC-related external carcinogens have been implicated. The presence of some unhealthy components inside the oral cavity, including residue dental roots and crowns, as well as improper dental prothesis, was identified to promote the malignant transformation of the normal oral epithelium due to its persistent physical stimulus. Besides, global nutrition deficiency might also be related to OSCC. Deficiency of vitamin A was identified to have a correlation with the occurrence of oral leukoplakia, a type of oral precancerous lesion (Sankaranarayanan et al., 1997). Loss of vitamin D might also act as a contributor to OSCC progression (Verma et al., 2020). Persistent intake of hot water and food is an acknowledged risk factor for esophagus carcinoma, and this stimulus, along with other stimulatory factors including pungent passing through the oral cavity, might also promote the formation of malignant oral lesions. In some special regions of the world, for example, New Zealand, where strong illumination exists throughout the year, UV radiation was also considered a possible carcinogen for skin carcinoma and OSCC (Yakin et al., 2017).

\section{ABNORMALITY OF GENOME LANDSCAPE IN OSCC}

Traditional concepts claimed that initiation and development of oral cancer are due to a sum of self- or risk factor-induced genetic changes that would lead to alterations in the activation of oncogenes and inactivation of tumor suppressor genes (PérezSayáns et al., 2009; Irimie et al., 2016). Multiple types of genes controlling cell proliferation, DNA repair, angiogenesis, and 
other pro-tumor biological processes have manifested significant variations between OSCC and normal oral tissues.

\section{ABNORMALITY OF IMMUNE MICROENVIRONMENT IN OSCC}

The current hot spot in cancer oncology research, apart from genetic variations, mainly lies in the tumor microenvironment, which contributes a lot to local tumorigenesis by promoting cellular proliferation, metabolism, metastasis, and so on (Casey et al., 2015). In the perspective of OSCC, although the heterogeneity of immune cell infiltration in the OSCC microenvironment makes it difficult to describe the total immunological landscape, more and more studies have been dedicated to figuring out this challenge.

\section{Abnormal Production of Cytokines}

Abnormal expression of chemokines plays an important part in the immunomodulation of the tumor microenvironment as recruitment and activation of immune cell subtypes are largely mediated by the interaction between chemokines and chemokine receptors (Nagarsheth et al., 2017). The chemokine-mediated regulating network exhibited its complexity via bidirectional protumor and anti-tumor functions (Figure 1).

IL-2 functions as an important growth factor for $\mathrm{T}$ cell subpopulations, and activation of $\mathrm{CD}^{+} \mathrm{T}$ cell differentiation by IL-2 has been verified. In addition, effector and memory $\mathrm{CD} 8^{+}$ $\mathrm{T}$ cell responses could also be induced by IL-2 (Spolski et al., 2018), indicating its crucial role in the T cell-mediated antitumor process.

A large amount of evidence indicated crucial roles of IL-10 in the anti-tumor process. $\mathrm{CD} 8^{+} \mathrm{T}$ cell function and memory could be ignited by IL-10 exposure (Foulds et al., 2006). Elevation of granzyme B and activation and interferon- $\gamma$ (IFN- $\gamma$ ) expression, along with subsequent CTL infiltration, have also been identified (Emmerich et al., 2012). Direct stimulation of NK cells by IL-10 would contribute to its anti-tumor effects (Lauw et al., 2000), while IL-10 could also indirectly mediate NK cell activation via inhibition of ROS secretion by TAMs (Mocellin et al., 2004).

IL-35 is another commonly acknowledged regulator in the tumor microenvironment. As a member of the IL-12 family, its immune suppressive role would render a pro-tumor status. Protumor neutrophils induced by IL-35 could result in malignant progression of local tumor tissues (Zou et al., 2017). In addition, Tregs accumulated in tumor sites are the main resource of IL-35, and anti-IL35 treatment showed a similar effect to that of the depletion of Tregs. Inhibition of Th17 cell growth and function by IL-35 were also discovered (Niedbala et al., 2007), indicating that IL-35 might inhibit anti-tumor effects partially through a Th17 blockade.

IL-6 is a crucial chronic inflammatory mediator, higher levels of which have been observed in multiple types of cancers. Several major pro-tumor activities, including growth, invasion, and angiogenesis, have been identified to be closely correlated with IL- 6 overexpression. In addition, the blockade of type 1 immune response (Tsukamoto et al., 2018), elevation of Treg cells (Kato et al., 2018), expansion of MDSCs, and activation of stromal fibroblasts could also be induced by IL-6, thus contributing to tumor development (Hanazawa et al., 2018).

IL-8 normally acts as a kind of chemokine, recruiting the accumulation of leukocytes (Alfaro et al., 2017). While in the tumor microenvironment, the high affinity of IL- 8 to CXCR1 and CXCR2, the activation of which has been demonstrated to play an important role in tumor progression (Campbell et al., 2013; David et al., 2016), would contribute a great deal to the malignant process. Besides, an IL-8-induced increase in MDSC recruitment would accelerate the chronic inflammatory status of local tumor sites (Chi et al., 2014).

Similarly, IL-17 also played pro-tumor roles during tumor progression. Chronic exposure of IL-17 would lead to a protumor microenvironment via production of inflammatory mediators, mobilizing myeloid cells and a phenotypic switch of stromal cells (Zhao et al., 2020).

TNF- $\alpha$ is a key pro-inflammatory cytokine, which exhibited a dual function in tumor progression. Stromal cells and cancer cells could both be sources of TNF- $\alpha$. On the one hand, high levels of cytotoxic potential from TNF- $\alpha$ could render destruction of tumor vasculature, necrosis and apoptosis of cancer cells, and facilitation of drug accumulation inside tumor sites. On the other hand, studies also showed that TNF- $\alpha$ secreted by host cells surrounding tumor tissues could instead construct an inflammatory status and promote tumor progression (Egberts et al., 2008; Sethi et al., 2008).

As for OSCC, differential production of some types of chemokines is significantly associated with carcinogenesis.

When it comes to chemokines, accumulations of CCL20, CCL18, CCL4, and CCL2 were identified to promote tumor progression in OSCC (Li et al., 2014; Lee et al., 2017; Wang et al., 2017; Lien et al., 2018). Meanwhile, gene polymorphisms of CCL4 and CCL5 were highly associated with OSCC susceptibility (Weng et al., 2010; Lien et al., 2017). These deregulated chemokines have been shown to play roles in microenvironmental immunomodulation via recruitment of Treg cells, macrophages, MDSCs, and so on (Nagarsheth et al., 2017). As for inflammatory cytokines, interleukin (IL) 6, IL-8, and tumor necrosis factor-alpha (TNF- $\alpha$ ) have been identified in terms of their potential roles as diagnostic biomarkers for OSCC (Sahibzada et al., 2017). Association between the gene polymorphism of IL-2 and OSCC has also been discovered (Singh et al., 2017). IL-23 could contribute to the progression of premalignant oral lesions to OSCC (Caughron et al., 2018), while IL-17 was significantly linked to the overall survival status of HNSCC (Lee et al., 2018). It is widely acknowledged that complex interacting networks of inflammatory cytokines could control recruitment, activation, and suppression of immune cells. Thus, the discussed abnormality of inflammatory cytokines in OSCC might result in a pro-tumor immune landscape in OSCC.

\section{Abnormal Tumor-Infiltrating Immune Cells}

Tumor-infiltrating cells are those immune cells located in the local tumor microenvironment, which have been identified to play crucial roles in either pro-tumorigenesis or antitumorigenesis and have significant prognostic value in cancer development (Shang et al., 2015). Immune cells inside the tumor 


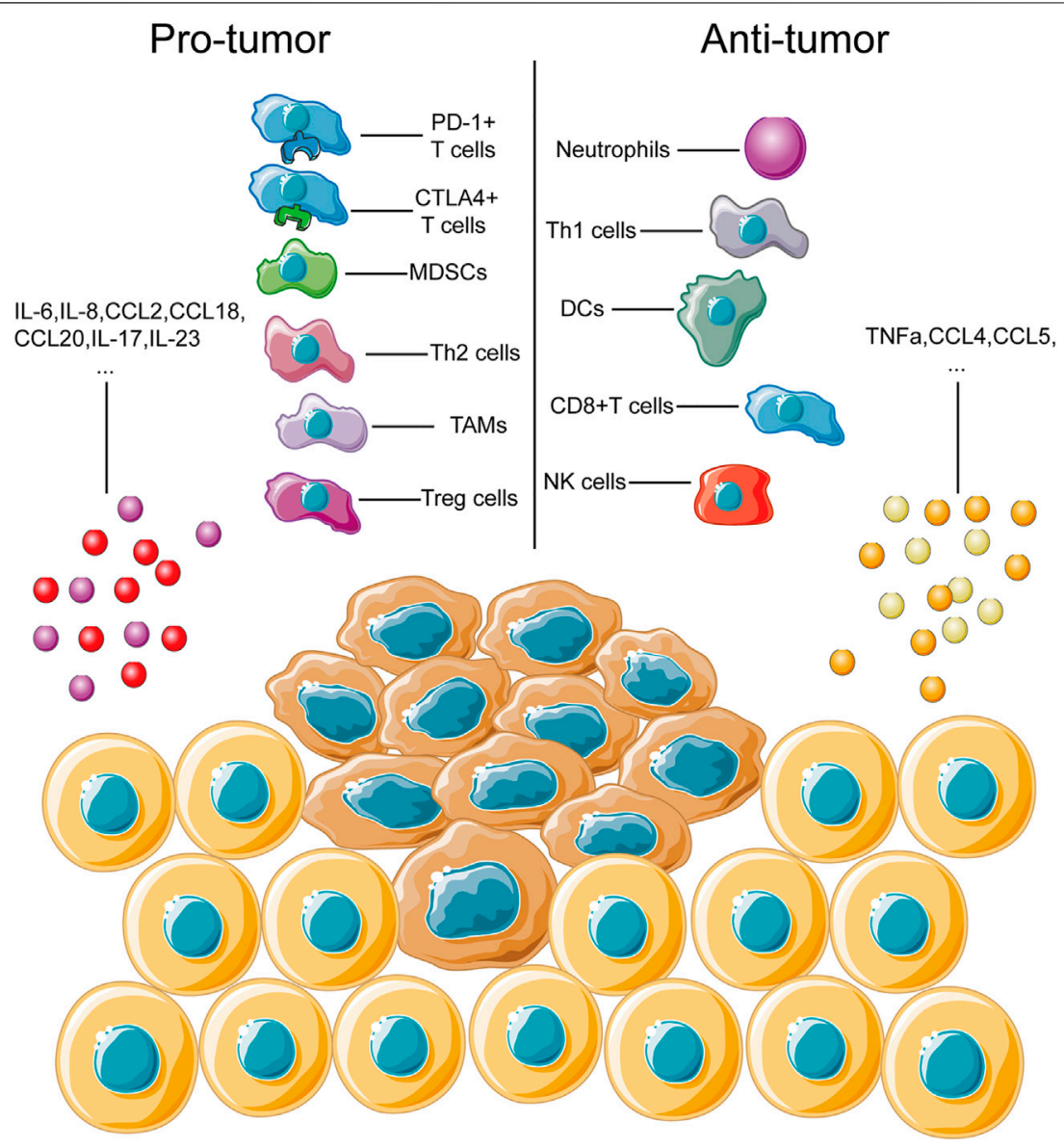

Oral squamous cell carcinoma

FIGURE 1 | Immune cells and cytokines associated with OSCC progression. This figure depicts the main types of immune cells and cytokines associated with progression of OSCC development. During OSCC progression, immune cells and cytokines could be divided into two groups, the pro-tumor part and the anti-tumor part. Immune cells, including PD $-1^{+}$and CTLA4 ${ }^{+} T$ cells and TAMs, have been identified to play roles in tumor progression through multiple pathways, as discussed above. Similarly, immune cells contributing to the anti-tumor process, Th1 cells and NK cells, for example, were also listed inside. A complete overview of immune cells involved in tumor development would help us better understand the complexity of immune regulation of OSCC.

microenvironment could commonly be divided into two groups, the myeloid cell subgroup and the lymphocyte subgroup, all of which work together to form a comprehensive and interactive immune regulating network to influence the complexity of the tumor immune microenvironment.

\section{Tumor-Related Myeloid Cells}

Traditionally, myeloid cells acted as major components for host protection. They have changed evolutionally as barriers against variant infections and contributors to tissue remolding. However, during tumor development, myeloid cells would play complicated roles (Gabrilovich, 2017).

\section{Myeloid-Derived Suppressor Cells}

Myeloid cells which are CD11b- and Gr-1-positive and exhibited a strong immune suppressive effect have now been defined as myeloid-derived suppressor cells (MDSCs). Main subtypes of MDSCs are polymorphonuclear (PMN-MDSCs) and mononuclear (M-MDSCs). Although the suppressive effect of MDSCs could cover multiple types of immune cells, $\mathrm{T}$ cells are their main targets (Gabrilovich et al., 2012). Production of NO and variant cytokines induced by M-MDSCs could efficiently suppress $\mathrm{T}$ cell activity, as a $\mathrm{NO}$-associated $\mathrm{T}$ cell receptor blockade would reduce the antigen presentation process (Koehn et al., 2015), while formation of antigen-specific $\mathrm{T}$ cell tolerance is a main mechanism for PMN-MDSCs (Gabrilovich et al., 2012). Besides, production of reactive oxygen species (ROS) is also essential for this process. On the other hand, MDSCs could also participate in the remolding process of the tumor microenvironment and tumor angiogenesis via VEGF, bFGF, and MMP9 (Casella et al., 2003; Shojaei et al., 2009).

\section{Neutrophils}

Neutrophils are the first line against multiple infections of the host. However, their plasticity in the tumor microenvironment puts them into both pro-tumor and anti-tumor roles (Giese et al., 
2019). Generation of ROS, reactive nitrogen species (RNS), and hydrogen peroxide could direct cancer cell-specific death, which is the main mechanism for neutrophil-induced anti-tumor roles (Granot et al., 2011), while in addition to their cytotoxic effect, abnormal production of ROS and RNS would result in oxidative DNA damage and genetic variations (Güngör et al., 2010). It is also well known that neutrophil-extracellular traps (NETs) generated in the tumor microenvironment would result in migration and invasion of cancer cells (Park et al., 2016). Secretion of MMPs from neutrophil granules might promote malignant development via migration, proliferation, and angiogenesis (Ardi et al., 2007; Das et al., 2017).

\section{Dentritic Cells}

Dendritic cells (DCs) are commonly regarded as the activator of $\mathrm{T}$ cells via transporting cancer-associated antigens. Initiation, polarization, and direction of $\mathrm{T}$ cells in the tumor microenvironment as well as recycling lymph nodes by DCs are the main mechanisms for DC-induced tumor suppression, during which the $\mathrm{CD}^{+} \mathrm{T}$ cell is their main target (Gardner et al., 2016). However, suppression of DCs in the tumor microenvironment would block this process, rendering a nonimmunogenic DC phenotype switch. Thus, stimulatory and suppressive signals in the tumor microenvironment aiming at DCs, cytokines, and cell-cell communication, for example, would regulate DC-related $\mathrm{T}$ cell immunogenic functions.

\section{Tumor-Associated Macrophages}

Tumor-associated macrophage (TAM) is a subtype of infiltrating macrophage contributing to local tumor growth, metastasis, and neovascularization (Zhu et al., 2017). Infiltrating TAMs in OSCC is also associated with tumorigenesis. CD163, a common marker for TAMs, was observed to be elevated in OSCC tissues (Stasikowska-Kanicka et al., 2018a), suggesting its possible relationship with oral carcinogenesis. Coincidentally, the same phenomenon was observed in oral precancerous lesions (Boas et al., 2013). Besides, CD204, another TAM marker, was shown to be linked to the progress from oral premalignant lesions to OSCC (Kouketsu et al., 2019). Using a xenograft model, irradiationinduced M2 macrophage accumulation showed the potential to promote oral tumor recurrence via enhancement of neovascularization (Okubo et al., 2016). The in vitro experiment remodeling the tumor environment confirmed the mutual promoting effect between oral cancer cells and TAMs (Essa et al., 2016), and the Gas6/Axl signaling pathway was further confirmed to enhance the epithelial-mesenchymaltransition of oral cancer cells (Lee et al., 2014). Apart from M2 macrophages, M1 subtype TAMs also played a positive role in OSCC (Xiao et al., 2018). In the early tumor stage, local resident macrophages act in cooperation with other innate immune cells to initiate inflammatory responses to reduce tumor progression, through some direct effects, for example, ROS generation, and some indirect pathways, such as regulation of Th1 responses (Joyce and Pollard, 2009; Murray and Wynn, 2011). It could be concluded from the above that TAM is significantly involved in the pathogenesis of OSCC.

\section{Tumor-Related Lymphocytes $\mathrm{CDB}^{+} \mathrm{T}$ Cell}

The $\mathrm{CD} 8^{+} \mathrm{T}$ cell is a generally recognized anti-tumor defender of the host and serves as one of the most crucial effector cells in anticancer immunity, dysfunction of which would result in a severe barrier for cancer elimination ( $\mathrm{He}$ et al., 2019). Loss of $\mathrm{CD}^{+} \mathrm{T}$ cells has contributed to tumorigenesis in many types of cancers. In OSCC, the $\mathrm{CD} 8^{+} \mathrm{T}$ cell was shown to decrease in either OSCC tissues or precancerous lesions (StasikowskaKanicka et al., 2018a). High $\mathrm{CD}^{+} \mathrm{T}$ cell percentage could also predict a better overall survival and disease-specific survival rate in OSCC (Shimizu et al., 2019). Immunological staining further revealed an increase in $\mathrm{CD}^{+} \mathrm{T}$ cells in OSCC with better prognosis (Stasikowska-Kanicka et al., 2018b). The expression level of PD-L1, an immune checkpoint blockade targeting cytotoxic $\mathrm{T}$ cells, was highly unregulated in OSCC (Stasikowska-Kanicka et al., 2018a; Stasikowska-Kanicka et al., 2018 b), indicating a loss-of-function status of T cells in OSCC. In the translational medical perspective, the anti-tumor effect of radiotherapy in OSCC was also verified to be partly attributed to the activation of $\mathrm{CD}^{+} \mathrm{T}$ cells (Suwa et al., 2006). These clinical experimental results together come to the conclusion that $\mathrm{CD} 8^{+}$ $\mathrm{T}$ cells play an anti-tumor role in OSCC, the abnormality of which would help in tumorigenesis.

\section{CD4 ${ }^{+}$T Cells}

$\mathrm{T}$ cells expressing CD4 glycoprotein are another crucial $\mathrm{T}$ cell subtype called the $\mathrm{CD} 4^{+} \mathrm{T}$ cell, and their functions in the tumor microenvironment are extremely complicated, due to multiple subgroups of $\mathrm{CD}^{+} \mathrm{T}$ cells, including Th ( $\mathrm{T}$ helper) 1 cells, Th2 cells, Th9, Th17, Th22, and T regular cells (Treg).

Th1 cells show some anti-tumor effects mainly via their large amount of IFN- $\gamma$ production, along with some chemokines to recruit and prime effector $\mathrm{CD}^{+} \mathrm{T}$ cells. Also, NK cells and M1 macrophages could be recruited and activated by Th1 cells in local tumor sites for tumor elimination (Nishimura et al., 1999). By targeting of tumor stroma and subsequent angiogenesis blockade, tumor growth could be inhibited in an IFN$\gamma$-mediated way by CD4 ${ }^{+} \mathrm{T}$ cells (Qin and Blankenstein, 2000).

Th2 cells have been verified to play some contradictory roles in tumor progression. Secretion of IL- 4 by Th2 cells would mediate transport of macrophages and eosinophils into tumor sites for anti-tumor actions (Tepper et al., 1989), and this immune transfer function is the main mechanism for the Th2-mediated anti-tumor effect. On the other hand, antigen-specific effector Th2 cells have been reported to promote cancer development, and IL- 5 secreted by them might be the reason behind this protumor effect (Tatsumi et al., 2002).

Th17 cells are an important subgroup participating in the antiinfection process. A pro-inflammatory microenvironment induced by secreted IL-17a and IL-23 would promote tumor progression via elevating angiogenesis and inhibiting infiltration of $\mathrm{CD}^{+} \mathrm{T}$ cells. Only a small amount of Th17-associated cytokine exposure could remarkably facilitate cancer progression (Lee et al., 2012), while some studies support that a high level of IL-17 would result in an anti-tumor immune status (Numasaki 
et al., 2005). This contradictory phenomenon suggested that the role of Th17 in tumor progression largely depends on the host status and local context.

Treg is a negative regulator in the adaptive immune system, suppressing the activation of immune responses and maintaining the immune balance (Sakaguchi, 2004). During tumor progress, excessive upregulation and activation of Treg cells would result in immune deficiency and subsequent immune escape of tumor cells, thus facilitating the development of tumorigenesis (Smigiel et al., 2014). In OSCC patients, elevated levels of Treg cell-associated cytokines were observed in peripheral blood (Gaur et al., 2014), while a higher frequency of Treg cells was also discovered in OSCC samples (Schwarz et al., 2008). Animal experiments using mice and dogs further verified an increase in Treg cells in OSCC (Horiuchi et al., 2010; De Costa et al., 2012). In tongue squamous cell carcinoma, a higher level of expression of Treg cells was significantly associated with a poorer survival rate, and accumulation of Treg cells was used to predict bad prognosis of patients (Hanakawa et al., 2014). Compared with healthy donors, levels of circulating Treg cells were also much higher in OSCC patients, along with a higher level of TGF- $\beta$, a Treg-associated cytokine (Lim et al., 2014). The above evidence together confirmed the pro-tumorigenesis value of Treg cells in OSCC.

\section{Natural Killer Cells}

The anti-tumor immunity of natural killer (NK) cells has long been regarded as a predominant effector against metastasis or hematological cancers, and more and more efforts have been applied to fully understand properties of NK cells (Guillerey et al., 2016). Escape of NK cell immune surveillance in OSCC tissues and inactivation of the $\mathrm{NK}$ cell status in peripheral circulation of OSCC patients has been recorded in clinical research (Dutta et al., 2015). Similarly, the downregulated NK cell status was also observed to be linked to higher invasive oral tumor areas (Türkseven and Oygür, 2010). A newly published metaanalysis indicated the possibility of the NK cell marker being a prognostic marker, considering the negative correlation between NK cell markers and the OSCC patient survival rate (Huang et al., 2019). The successful curative effect of NK cell immunotherapy in OSCC identified in an in vivo model further confirmed the crucial anti-tumor role of NK cells in OSCC (Greene et al., 2020).

\section{OSCC CARCINOGEN-INDUCED IMMUNE ABNORMALITIES}

As predominant contributors to the progress of OSCC, multiple OSCC-related carcinogens, including smoking, drinking alcohol, chewing areca nuts, periodontal infection, and oral sexual behavior, have all been proven to be related to local immune abnormality to a great extent. A complete understanding of the immune status induced by carcinogens would help in possible recognition of the immune landscape of carcinogen-induced OSCC.

\section{Cigarette}

Cigarettes are a well-known risk factor for many oral diseases, including periodontitis (Kinane et al., 2017), halitosis (Jiun et al.,
2015), oral leukoplakia (Granero Fernandez and Lopez-Jornet, 2017), and OSCC (Blot et al., 1988). Previous studies about the effect of smoking on carcinogenesis mainly focused on aberrant genetic alterations brought on by harmful compounds inside cigarettes. Accumulation of DNA adducts and oxidative DNA damage induced by tobacco smoking have been identified for a while (Phillips, 2002), and the subsequent genetic mutational signatures, such as TP53, P73, and MDM2 (Misra et al., 2009), were listed clearly, using sequencing methods (Alexandrov et al., 2016). However, little attention was cast onto the influence of microenvironmental changes caused by tobacco. The oral cavity is a local microenvironment whose stability would be extremely changed due to tobacco smoking (Figure 2). Thousands of reactive oxygen species (ROS) are generated in burning cigarettes (Huang et al., 2005), and ROS-attacked epithelial cells and cancer cells in the oral cavity would secrete lots of inflammatory mediators, thus leading to imbalance of host immunity in the oral cavity. It is evidenced that cigarette smoke could result in upregulation of IL-8 (Barnes, 2016) and downregulation of IL-12 by the oral epithelium (Vassallo et al., 2005a). As IL-12 is a main inducer of the Th1 response (Trinchieri, 2003), the phenomenon coincides with the observation that cigarette smoking would result in suppression of Th1 responses and generation of Th2 inflammatory reaction

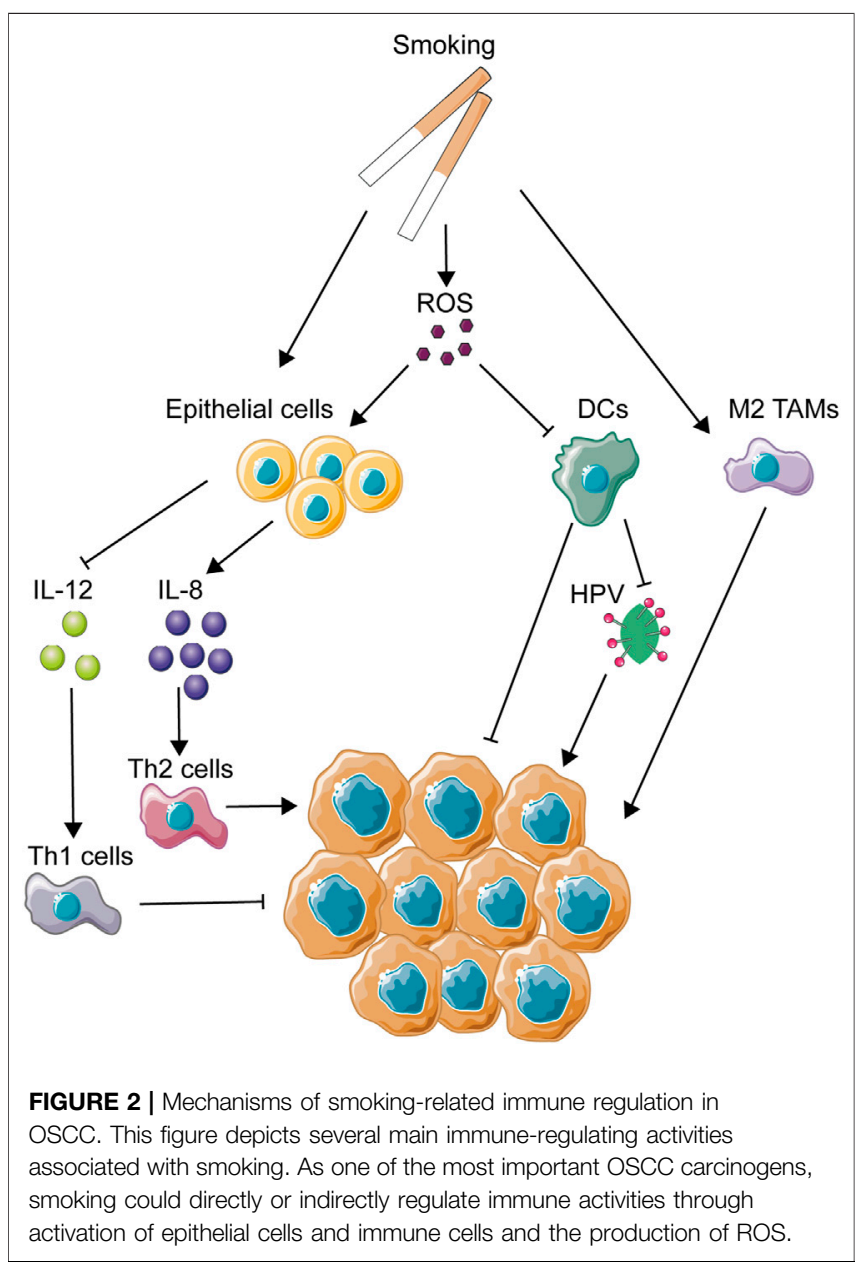


(Cozen et al., 2004), and excessive Th2 response would break the balance between Th1 and Th2. As has been known, Th2 immune polarization might result in some unexpected effects in carcinogenesis. CCL5-mediated recruitment and differentiation of Th2 cells enhanced the primary tumor burden and pulmonary metastases of luminal breast cancer (Zhang et al., 2015). NLRP3activated polarization of Th2 cells also had a tumor-promoting impact on pancreatic cancer (Daley et al., 2017), further identifying the immunosuppressive role of Th2 in carcinogenesis. On the other hand, patients with higher accumulation of Th1 exhibited better and prolonged survival (Tosolini et al., 2011), precise evidence for the anti-tumor effect of Th1. Furthermore, some chemotherapies targeted at the tumor microenvironment also aim to enhance Th1 cytokine levels as an anti-tumor pathway (Berlato et al., 2017). Thus, smokinginduced imbalance of Th1/Th2 might be speculated to play a role in development of OSCC from an immunological perspective. Besides, IL-8 could act as a pro-tumorigenesis cytokine with its promotion of tumor proliferation, migration, and maintaining of stemness (Chen et al., 2014; Huang et al., 2015; Ding et al., 2017). As reported, the release of IL-8 induced by cigarette smoke (CS) was mainly from macrophages (Facchinetti et al., 2007) and airway epithelial cells (Mio et al., 1997). Interestingly, several research studies have reported that IL-8 was induced in oral squamous cell carcinoma cells (Tsunoda et al., 2016) and gingival epithelial cells (Mahanonda et al., 2009). Thus, upregulation of IL-8 by CS might play an important role in CS-induced tumorigenesis.

CS could also impose a great influence on immunological functions of dendritic cells. It has been reported that some components of CS, such as ROS, nicotine, and other chemicals inside, were involved in the influence on DCs (dendric cells), causing the suppression of $\mathrm{DC}$-induced $\mathrm{T}$ cell activation and proliferation (Vassallo et al., 2005b; Kroening et al., 2008; Vassallo et al., 2008). DCs are considered to be main activators for both innate immunity and adaptive immunity, being highly efficient in generating fast and fierce immunological responses (Constantino et al., 2017). However, under the immunosuppressive influence of the tumor microenvironment, DCs always show a biological dysfunction in the cancerous background, as a way to help tumor evasion (Tang et al., 2017). Due to its central role in the initial phase of immunity activation, DC-based immunotherapy has been used in clinical trials since the mid-1990s and has been applied in many types of cancers such as melanoma, prostate cancer, malignant glioma, and renal cell carcinoma (Anguille et al., 2014). Thus, CSinduced dysfunction of DCs is considered as a contributor to the malignant development of the tumor microenvironment. In addition, CS extract has also been found to suppress production of antiviral cytokines from DCs (Mortaz et al., 2009). In nasopharyngeal carcinoma, CS extract has been proved to promote the infection of the Epstein-Barr virus (EBV), the enhancement of which is closely associated with the malignant development of nasopharyngeal carcinoma (Huang et al., 2017). The proportion of HPV-related OSCC has increased in the past 30 years in a longitude clinical survey in America (Chaturvedi et al., 2008), emphasizing the importance of HPV infection in OSCC development. Thus, it could be speculated that the decrease in antiviral capacity caused by CS might promote the colonization and replication of HPV in the oral cavity.

Smoking was found to increase the aggregation of alveolar macrophages but impair the normal functions of macrophages (Kotani et al., 2000; Hodge et al., 2003). The same phenomenon was identified in vitro (Kirkham et al., 2004). As is known to all, dysfunction of macrophages might help to promote the development of tumors. In addition, smoking could induce the polarization of M2 macrophages in alveoli (Bazzan et al., 2017). In an in vivo mouse model, smoking was identified to induce the polarization of tumor-associated macrophages and promote the development of pancreatic cancer in this way (Kumar et al., 2015). Thus, the dysfunction and M2 polarization of macrophages caused by smoking might partly explain the malignant transformation of the tumor microenvironment, leading to OSCC development as a result.

On the other hand, CS is a crucial modulator of host response to pathogens (Nuorti et al., 2000). Smokers are shown to be more likely to get infection of Streptococcus pneumoniae and Tuberculosis (Padrao et al., 2018). This feasibility of pathogen colonization might suggest a dysfunction of host immunity and destruction of microbial balance, leading to a low resistance to extraneous pathogens. Recently, the relationship between oral microbial dysbiosis and tumor development has been a hot topic, and a lot of evidence has revealed microbial dysbiosis as a contributor to carcinogenesis. Smoking was strongly identified to be involved in oral microbial variations through some clinical trials with large amounts of samples (Wu et al., 2016; Yu et al., 2017). Microbial diversity was decreased in smokers, and there were a reduction of phylum Proteobacteria and genera Capnocytophaga, Peptostreptococcus, and Leptotrichia and enhancement of Atopobium and Streptococcus. These abnormal changes of host microbial composition caused by smoking might be one of the reasons for the CS-induced effect of carcinogenesis.

\section{Alcohol}

Alcohol abuse has been implicated as a high risk factor in many types of cancers, including OSCC (Ng et al., 1993), esophageal cancer (Castellsagué et al., 1999), larynx cancer (Bosetti et al., 2002), colorectal cancer (Cho et al., 2004), and pancreatic cancer (Korc et al., 2017). Alcohol dehydrogenase (ADH) and aldehyde dehydrogenase (ALDH) play crucial roles in the regular conversion of ethanol to acetate. When it comes to carcinogenesis, traditional opinions about alcohol-induced carcinogenesis support the abnormal metabolism of ethanol caused by variations of $\mathrm{ADH}$ - and ALDH-encoding genes serving as main contributors (Jelski et al., 2009). For example, this abnormality of ethanol metabolism could lead to increased generation of ROS from epithelial cells, which then activates cellular pathways, such as the nuclear factor $\kappa \mathrm{B}(\mathrm{NF}-\mathrm{\kappa B})$ pathway and the mitogen-activated protein kinase (MAPK) pathway ( $\mathrm{Wu}$, 2006; Morgan and Liu, 2011), causing the malignant transformation of tumor cells. In addition, the RNS level of the epithelium was also elevated by alcohol stimulation. Accumulation of ROS and RNS would indirectly modify the 
immune microenvironment via its suppressive effect on $\mathrm{T}$ cells, NK cells, and macrophages (Figure 3). Besides this direct carcinogenic effect of alcohol, the function of host immunity is also under significant burden due to alcohol intake, which might partly explain the carcinogenesis of alcohol.

Alcohol intake, either acute or chronic, poses a great burden on NK cells. Alcohol abuse has long been regarded as a promoter for the development of hepatic diseases, such as hepatitis viral infection and liver fibrosis. It is reported that chronic ethanol consumption would accelerate virus-induced hepatitis through suppression of NK cell accumulation and cytotoxicity ability (Pan et al., 2006). Similarly, ADH3, a crucial enzyme in the metabolic process of alcohol, has great correlation with the development of hepatic fibrosis due to its suppression of NK cells (Yi et al., 2014). Abrogation of the antifibrotic effect of NK cells caused by alcohol was seen to increase the severity of alcoholic liver fibrosis (Jeong et al., 2008). In alcoholic hepatitis, a decreased frequency and reduction of the degranulation capacity of NK cells were also observed compared with healthy ones (Støy et al., 2015). When it comes to cancer development, alcohol abuse could also explain its carcinogenesis through $\mathrm{NK}$ cell variation, as acute alcohol ingestion has been demonstrated to cause a marked reduction of NK cell activity and, in this way, promote the tumor metastasis in vivo (Ben-Eliyahu et al., 1996). Metastasis of colon cancer cells into the liver was also increased by treatment of chronic alcohol consumption in a preclinical model ( $\mathrm{Im}$ et al., 2016). In

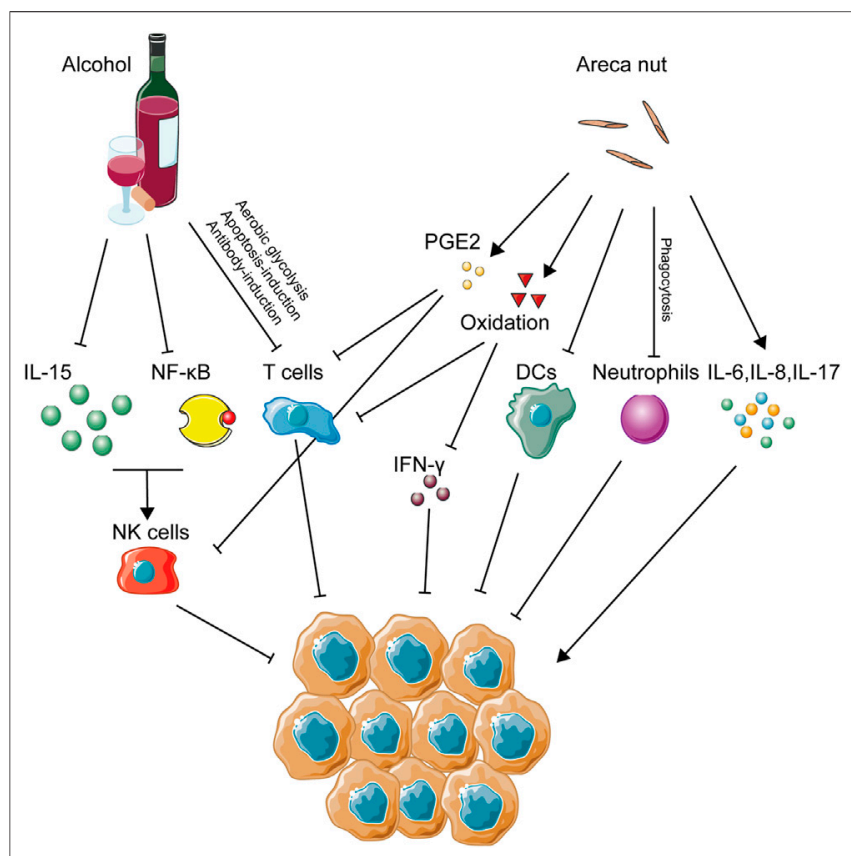

FIGURE 3 | Immune activities caused by alcohol and areca nut consumption in OSCC. This figure depicts the immune-regulating networks induced by alcohol and areca nuts during OSCC development according to related studies. Specifically, inhibition of NK cells, T cells, DCs, and neutrophils, several main anti-tumor immune cells, was a remarkable feature of immune abnormalities induced by alcohol and areca nuts, indicating that immune inhibition might be excessively crucial in OSCC associated with these two carcinogens. perspective of the count variation of NK cells, alcohol consumption has been identified to decrease the number of NK cells in the spleen (Blank et al., 1991) and peripheral lymph nodes (Zhang et al., 2011). Furthermore, the balance of thymus-derived and bone marrow-derived NK cells was also destroyed by alcohol intake (Zhang and Meadows, 2008). Besides, cytotoxicity and cell activity of NK cells was downregulated by treatment of alcohol (Wu et al., 1994), and enzymatic activity of granzyme A and B expressed by NK cells was suppressed, resulting in the loss of cell viability of NK cells (Spitzer and Meadows, 1999). On the other hand, some research focused on the explanations for alcohol-induced suppression of NK cells. Alcohol consumption could render a variation of the autonomic nervous system and reduction of pro-inflammatory cytokines from neuroendocrine and immune cells, leading to suppression of NK cell cytolytic activity (Boyadjieva et al., 2006; Chen et al., 2006). Downregulation of IL15 induced by alcohol consumption seemed like a way to suppress the availability of NK cells (Zhang et al., 2017), and this observation has been confirmed by a rescue experiment (Zhang and Meadows, 2009). Moreover, activity of the NF- $\kappa \mathrm{B}$ pathway in NK cells, a crucial pathway for immune activation, was also suppressed by alcohol treatment (Zhou and Meadows, 2003).

$\mathrm{T}$ cell function is also under the influence of alcohol drinking. Alcohol-derived acetaldehyde has been proved to pose severe toxicity to the immune system, and recent study has confirmed its role in the downregulation of $\mathrm{T}$ cell function via inhibiting aerobic glycolysis and hampering the energy source of $\mathrm{T}$ cells (Gao et al., 2019). An in vivo experiment using ethanol-fed mice proved that ethanol could enhance the antibody-induced $\mathrm{CD} 4^{+}$ $\mathrm{T}$ cell immunosuppression and thus promote tumorigenesis (Hunt et al., 2000). A chronic alcohol treatment was identified to accelerate the immunosenescence process of $\mathrm{CD}^{+} \mathrm{T}$ cells of rhesus macaques (Katz et al., 2015). Besides, an in vitro experiment showed that alcohol consumption could inhibit the $\mathrm{T}$ cell proliferation rate compared with water consumption, and an increase in some pro-tumor immune groups of cells, such as Treg cells and MDSCs, might also impair the function of T cells (Zhang and Meadows, 2010). The apoptosis of T cells would also be activated by the alcohol treatment via downregulation of the vitamin D receptor (Rehman et al., 2013).

\section{Areca Nuts}

It is well known that the habit of chewing Areca nuts has been widely popular in Southeast Asia, and its positive role in the development of oral precancerous lesion and OSCC has been fully accepted as well (Li et al., 2016). Apart from its genotoxicity, the areca nut might also affect the progress of oral malignant transformation via immunomodulation (Figure 3). For lymphocytes, the DNA synthesis process was identified to get inhibited long before (Yang et al., 1979). This phenomenon posed the hypothesis that areca nuts might decrease the immunity of lymphocytes. Further study confirmed that $\mathrm{T}$ cell activation and IFN- $\gamma$ production were suppressed by areca nut treatment through induction of oxidative stress (Wang et al., 2007). When it comes to immune cell function, the phagocytosis of neutrophils (Hung et al., 2006), the adhesion and migration of 
mononuclear leukocytes (Chang et al., 2014), and the differentiation of dendric cells from monocytes (Wang et al., 2012) were all proven to decrease due to areca nuts. In the perspective of inflammatory cytokines, treatment of human immune cells using areca nut extract was identified to increase multiple inflammatory cytokines, such as TNF- $\alpha$, IL6, IL8, cyclooxygenase-2 (COX2), and prostaglandin E2 (PGE2) (Chang et al., 2009; Chang et al., 2013; Faouzi et al., 2018), as well as decrease the level of IL2 production by spleen cells (Selvan et al., 1991). As for oral keratinocytes, production of PGE2, Prostaglandin I2 (PGI2), IL-6, and TNF-a was also enhanced due to areca components (Jeng et al., 2000; Jeng et al., 2003). Expressions of IL-2 and IL-2 receptor by $\mathrm{CD}^{+}$cytotoxic T lymphocytes (CTLs) and tumor-infiltrating lymphocytes (TILs) were also reduced under the influence of PGE2, while PGE2 induced $\mathrm{CD}^{+}$Th2 cell activation (Wustrow and Mahnke, 1996; Li et al., 2013). As mentioned above, TILs are lymphocytes that migrate from the blood to the tumor, playing crucial roles in either pro-tumorigenesis or anti-tumorigenesis. Among them, $\mathrm{CD}^{+}{ }^{+} \mathrm{Th} 2$ cells promote tumor growth, while CTLs inhibit tumorigenesis (Lauerova et al., 2002; Farhood et al., 2019). In other words, PGE2 serves as an immunosuppressor contributing to the induction of $\mathrm{CD} 4^{+} \mathrm{Th} 2$ cells and the pro-tumor efficacy of TILs. Circulating the immune complex, known to exhibit an immunosuppressive effect on NK cells and CTLs, was detected to accumulate more frequently in areca chewers than in healthy controls (Remani et al., 1988). A large-population experiment using flow cytometry and immune-staining reveals that IL-17 was highly expressed in areca chewers (Quan et al., 2020). Exposure of areca extracts was shown to induce the increasing secretion of IL6 and IL- 8 by peripheral blood mononuclear cells (Chang et al., 2006). In an animal model, arecoline receivers exhibited a low splenic lymphocyte proliferation rate and a high apoptosis rate (Dasgupta et al., 2006). Similarly, production of IL-8 from oral squamous cancer cells was also increased due to exposure of arecoline (Cheng et al., 2000). PBMC isolated from areca chewers exhibited a higher level of DNA damage markers in circulating lymphocytes (Liu et al., 2004).

\section{Periodontal Infection}

Periodontitis, one of the most common diseases inside the oral cavity, is largely caused by poor oral hygiene status and oral microbial dysbiosis (Lertpimonchai et al., 2017; Meuric et al., 2017). Periodontitis is featured by the dysbiotic inflammatory status (Hajishengallis, 2015), which is highly associated with inflammatory microenvironmental abnormality (Figure 4). Most of pathogenic oral bacteria are Gram negative ones, sharing a similar ability to induce higher concentration of cytokines from oral epithelial cells, such as IL-6, IL-1 $\beta$, TNF$\alpha$, and IL-8 (Ha et al., 2016; Cardoso et al., 2018), and overexpression of these inflammatory cytokines contributes to the abnormality of the microenvironment as discussed above. In particular, some periodontal pathogenic microbiota has been reported to impose immunosuppression on the local focus. $F$. nucleatum, a common periodontitis-associated bacterium, was identified to recruit MDSCs, a kind of tumor-infiltrating immune cell with anti-immunity ability (Kostic et al., 2013). M2

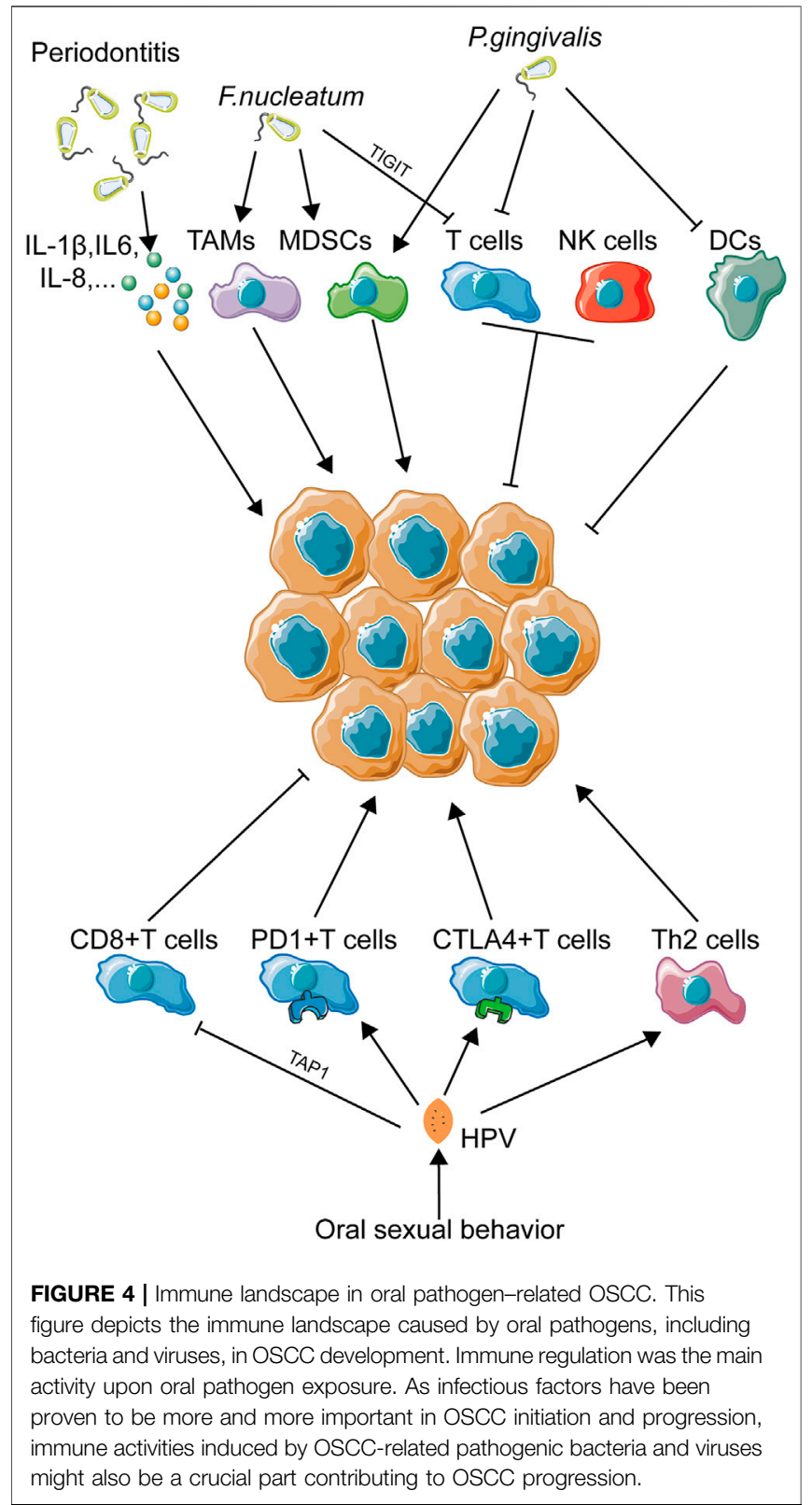

polarization, leading to the differentiation of tumor-associated macrophages, was also observed to be induced by F. nucleatum (Chen et al., 2018). TIGIT, a membrane protein of many immune cells, such as NK cells and T cells, could also be modulated by $F$. nucleatum, resulting in loss of function of NK cells and cytotoxic $\mathrm{T}$ cells (Gur et al., 2015). Another common periodontal pathogen, $P$. gingivalis, is also involved in immunomodulation. P. gingivalis was identified to silence innate immune response partly by inactivating DCs (Abdi et al., 2017). In vivo experiment exhibited that $P$. gingivalis infection promoted the expansion of MDSCs (Su et al., 2017). Disturbance of the Th1/Th17 balance was also induced by $P$. gingivalis (Monasterio et al., 2019), while suppression of IL-2 accumulation in $\mathrm{T}$ cells (Khalaf and Bengtsson, 2012) and reduction of CXCL10 expression caused by $P$. gingivalis infection (Jauregui et al., 2013) might be used to 
partly explain this phenomenon. M2 polarization was also elicited by $P$. gingivalis and could promote carcinogenesis in HNSCC (Utispan et al., 2018).

\section{Oral Sexual Behavior}

With the development of society and subsequent changes in traditional concepts, the frequency of oral sexual behavior has mounted to a high level, especially in young adults (Holway and Hernandez, 2018). This behavior shift makes the oral cavity exposed to a totally new environment. Clinical trials have revealed that changes in sexual behaviors trend toward a higher incidence of oral HPV infection (Chaturvedi et al., 2015). This phenomenon just coincides with the conclusion that the percentage of HPV-positive oropharyngeal carcinomas has risen from $16.3 \%$ in the 1980 s to $72.7 \%$ in the 2000 s (Chow, 2020). Obviously, oral sex-mediated HPV exposure has become a newly emerging risk factor for oral and pharyngeal carcinomas. It is worth noting that HPV infection has been identified to play a crucial role in local immune disruption (Figure 4). Studies have revealed that $\mathrm{HPV}^{+} \mathrm{HNSCC}$ patients are more likely to exhibit an abnormal tumor immune microenvironment (Gameiro et al., 2018). A meta-analysis concludes that dysfunction of T cells plays a great part in HPV-induced immune deficiency, while the abnormality of macrophages, Tregs, and MDSCs remains unclear (Lechien et al., 2019). Viral protein E7 could reduce expression of TAP1, as a way to inactivate cytotoxic T cells (Einstein et al., 2009). Infection of HPV would result in downregulation of pro-inflammatory cytokines and upregulation of anti-inflammatory cytokines, such as IL-10 (Mota et al., 1999). In cervical cancer, another HPV-associated carcinoma, loss of $\mathrm{T}$ cell cytotoxicity, increase in immunosuppressive Th cell infiltrating, and secretion of immunosuppressive cytokines are all associated with HPV infection (Piersma, 2011). In HNSCC, a large-population transcriptome analysis revealed a $\mathrm{T}$ cell dysfunction and $\mathrm{T}$ cell exhaustion signatures in HPV-positive patients (Krishna et al., 2018). Furthermore, overexpression of PD-1 and CTLA-4 was observed in HPV-positive HNSCC tissues, which indicated a lossof-function status of $\mathrm{CD}^{+} \mathrm{T}$ cells due to HPV infection (Kansy et al., 2017). In short, abnormality of the T cell status induced by HPV infection might be closely related to OSCC development.

\section{RISK FACTOR-BASED IMMUNOTHERAPEUTIC STRATEGY}

Until now, surgical operation is still the first choice for OSCC treatment. Heterogeneity acts as one of the main traits in head and neck squamous cell carcinoma (HNSCC) (Schubert et al., 2020), and poor clinical outcomes of radiation and chemical treatment were partly due to the heterogeneity of OSCC patients (Kagohara et al., 2020). Immune phenotypes of HNSCC classified by the heterogeneity of immune landscapes among HNSCC patients have been built up successfully (Feng et al., 2020). This result further indicated that immune heterogeneity of HNSCC might be summarized into a statistical rule, which might be used for classification of HNSCC patients with different immune statuses. A recent study has identified that smoking could exert an immunosuppressive effect on the HNSCC tumor microenvironment with the help of multiomics analysis (de la Iglesia et al., 2020). This discovery just coincides with the above hypothesis that oral cancer-related risk factors might greatly account for the abnormality of the immune status. In the perspective of tumor therapy, immunotherapeutic strategies for OSCC ought to be dependent on intratumor heterogeneity to achieve better clinical outcomes (Mroz et al., 2020). Thus, in consideration of the correlation between risk factors and immune variations, a new concept is brought out that combination of patient risk factor information and immune status detection might be valuable for directing individualbased immunotherapy for OSCC patients (Figure 5).

\section{Check Point Blockade Therapy Anti-PD-(L)1 Treatment}

Programmed death ligand 1 (PD-L1) is often expressed on the surface of antigen-presenting cells (APCs), tumor cells, etc., and it can bind to PD-1 on the surface of activated T cells, leading to the exhausted status of T cells (Goodman et al., 2017). Anti-PD-(L)1 treatment could be applied due to its role in reducing $\mathrm{T}$ cell apoptosis and enhancing recruitment of $\mathrm{T}$ effector cells to tumor sites (Dong et al., 2002). Downregulation of $\mathrm{T}$ cell function is a significant feature in OSCC, which is a plausible reason for possible application of anti-PD-(L) 1 treatment in OSCC. As reported, anti-PD-1 (aPD1) immunotherapy has been proven to be effective in lymphomas (Goodman et al., 2017), melanoma (Wang et al., 2016), and non-small-cell lung cancer (Xia et al., 2019). Increased expression of PD-1 and PD-L1 was observed in oral lesions progressing to OSCC compared to non-progressing dysplasia (Dave et al., 2020). In addition, several reports revealed that recurrent/metastatic HNSCC patients treated with anti-PD1 showed a significantly prolonged survival compared with standard treatment (Ghanizada et al., 2019). Additionally, high expression of PD-1 was observed in exhausted NK cells, and antiPD1 therapy could reverse this condition in many cancers (Romero, 2016; Li et al., 2018). So the anti-PD-(L)1 method might also be used as the NK cell-targeted method in alcoholrelated OSCC. Subsequent clinical experiments identified that anti-PD1 therapy achieved a better prognostic outcome in $\mathrm{HPV}^{+}$ cancer patients than $\mathrm{HPV}^{-}$controls (Ferris et al., 2016). Besides, a systemic meta-analysis confirmed that $\mathrm{HPV}^{+} \mathrm{HNSCC}$ patients could benefit more from anti-PD1 immunotherapy, further ensuring the role of the PD1 blocking method in the treatment of $\mathrm{HPV}^{+}$OSCC patients (Galvis et al., 2020). In conclusion, anti-PD-(L)1 treatment is an optional method for all subgroups of OSCC discussed above.

\section{Anti-CTLA-4 Treatment}

The cytotoxic T-lymphocyte-associated antigen 4 (CTLA-4) is a critical receptor for the negative regulation of $\mathrm{T}$ cell activation (Rowshanravan et al., 2018). Although elimination of CTLA-4 can result in several diseases including autoimmune diseases, effective anti-tumor immunity sometimes requires the blockade of CTLA-4 (Brunner-Weinzierl and Rudd, 2018; Hosseini et al., 2020). 


\section{Risk factor-based Immunotherapeutic Strategy}

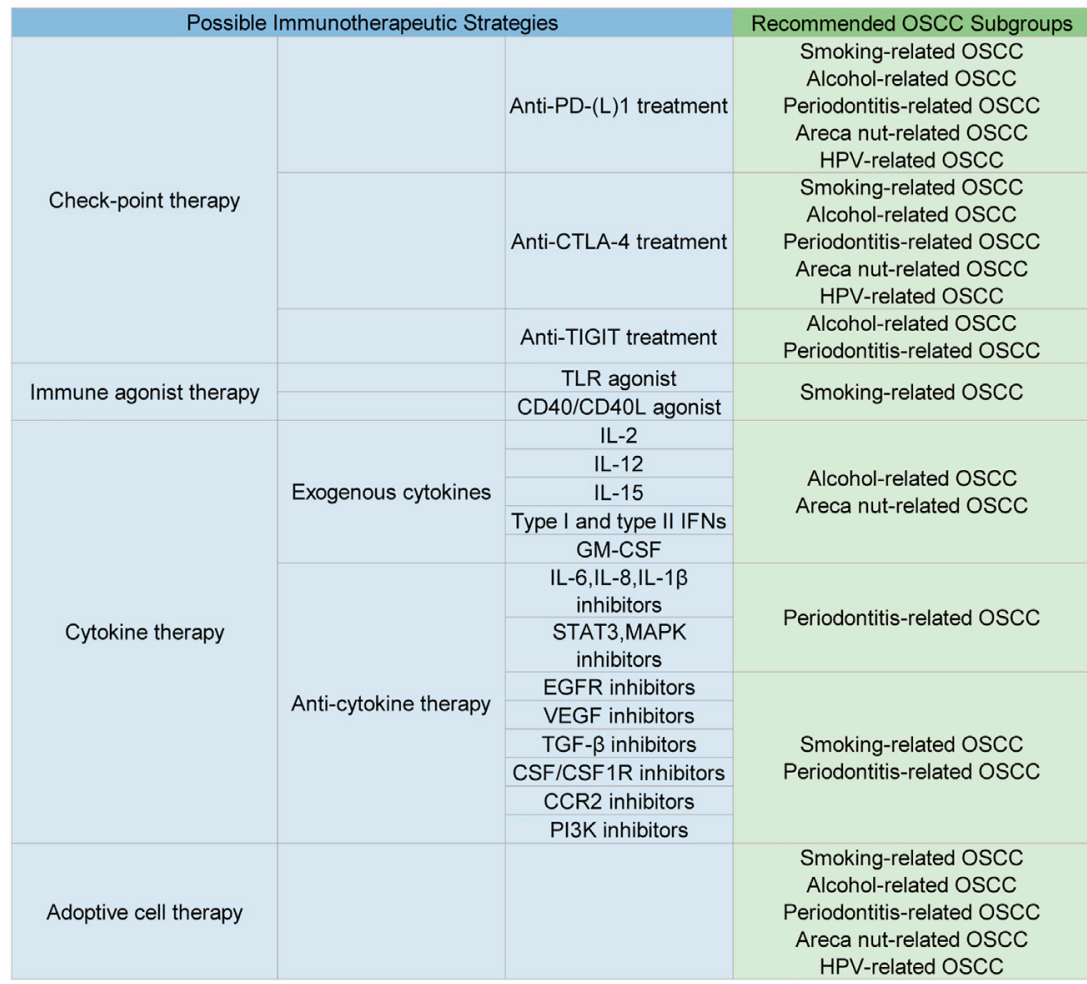

FIGURE 5 | Immunotherapeutic strategies based on the specific carcinogen-related immune status. This figure depicts multiple types of immunotherapeutic strategies and subsequent OSCC subgroups suitable for each kind of strategy. As discussed in this manuscript, carcinogens would result in a specific aberrant immune status for OSCC patients, which just explained drug resistance and individual variations of immunotherapeutic responses. Thus, possible personalized immunotherapeutic strategies based on different carcinogen-induced types of the OSCC local immune status were listed above and might achieve a better clinical outcomes.

Wang et al. (2019) found that syngeneic animal models of tobacco-associated oral cancers have higher response rates to anti-CTLA-4 immunotherapy than to anti-PD1 treatment. Anti-CTLA-4 treatment could also increase IFN- $\gamma$-producing $\mathrm{CD} 4^{+}$Th1 cells, which is necessary for overcoming the imbalance of Th1/Th2 caused by smoking (Chen et al., 2009). On the other hand, downregulation of $\mathrm{T}$ cell function was also observed in alcohol-drinking patients. Depending on this point, anti-PD-(L) 1 and anti-CTLA4, two common check-point inhibitors for $\mathrm{T}$ cells, could be used as discussed above. In addition, based on the overexpression of CTLA-4 observed in $\mathrm{HPV}^{+} \mathrm{HNSCC}$ tissue samples, a combination of anti-PD1 and anti-CTLA-4 therapies might be likely to achieve a better clinical outcome in HPV-related OSCC patients.

\section{Anti-TIGIT Treatment}

The $\mathrm{T}$ cell immunoreceptor with immunoglobulin and ITIM domain (TIGIT) is a promising new target along with PD-(L)1 and CTLA-4 for cancer immunotherapy, and the blockade of TIGIT and PD-L1 were found to act synergistically on T cells and NK cells' effector functions (Johnston et al., 2014). Zhang et al. (2018) found that the inhibition of TIGIT could prevent NK cell exhaustion and promote NK cell-dependent tumor immunity in several tumor mouse models. Since the dysfunction of NK cells plays an important pathogenic role in drinking patients, antiTIGIT therapy might be effective in the treatment of alcoholrelated OSCC. In addition, due to the binding ability of $F$. nucleatum to TIGIT and subsequent downregulation of $\mathrm{NK}$ cells and $\mathrm{T}$ cells, some anti-TIGIT antibodies, MK-7684, for example, might work against the tumorigenesis effect of $F$. nucleatum specifically. As anti-tumor therapies targeting TIGIT have achieved great success recently, this method might also be useful in OSCC patients with high F. nucleatum abundance (Solomon and Garrido-Laguna, 2018).

\section{Immune Agonist Therapies}

Although many patients have benefited from checkpointblockade immunotherapies, and the overall survival of patients was significantly prolonged due to these therapies, substantial patients do not respond to these strategies, and several drugresistance mechanisms have been identified (Dempke et al., 2017). To overcome low efficiency of checkpoint-blockade immunotherapies for some OSCC patients, more and more investigations begin to focus on co-stimulatory agents. Tolllike-receptor (TLR) agonists could promote innate immune cells (e.g., macrophages and plasmacytoid DCs), while PD-1 
inhibitors act on adoptive immune cells (e.g., activated $\mathrm{T}$ cells). Sato-Kaneko et al. (2017) identified that combination therapy with TLR agonists and anti-PD-1 increased antigen-presenting functions of TAMs and the infiltration of IFN $\gamma+\mathrm{CD} 8+\mathrm{T}$ cells in head and neck tumors, thus suppressing tumor growth. CD40 is a TNF receptor superfamily member expressed on both immune and non-immune cells, and CD40/CD40L agonists could upregulate antigen presentation machinery, enhance $\mathrm{T}$ cell proliferation and cytokine production, thus acting in the regression of tumors (Bennett et al., 1998; Mayes et al., 2018; Vonderheide, 2020). Considering the contribution of CS-induced dysfunction of DCs to the development of smoking-related OSCC, these immunotherapies might be effective strategies targeted at these subgroups.

\section{Cytokine Therapy Exogenous Cytokines}

IL-2 was the first approved cytokine for boosting NK cells clinically (Floros and Tarhini, 2015) and was mainly used to produce lymphokine-activated NK cells. Similarly, IL-15 and IL-12 were also pro-inflammatory cytokines playing important roles in the development, homeostasis, and cytotoxicity of NK cells (Floros and Tarhini, 2015). For OSCC patients with a drinking habit, a great burden on NK cells was a significant feature, and these cytokines were the most commonly applied cytokines for NK cell activation, clinically. Apart from their roles in the maturation of NK cells, IL15 and IL-12 can also lead to IFN $\gamma$ production (Berraondo et al., 2019). Both type I and type II IFNs have been reported to induce the anti-tumor activities of almost all immune cells, especially the maturation of DCs for antigen presentation and the negative regulation of MDSCs (Parker et al., 2016). Besides, oncolytic virus talimogene laherperepvec (T-VEC), which could express myeloid cell growth and survival factor GM-CSF (Andtbacka et al., 2019), might also be used to ameliorate the loss of DCs in smoking OSCC patients. Considering that inactivation of DCs and induction of MDSCs were both related to high abundance of $P$. gingivalis and areca-chewing habits, these cytokines mentioned above might be effective for those OSCC patients. In addition, owing to the significant decrease in IL-2 induced by areca-chewing, an extraordinary supplementation of IL-2 might also help to some extent.

\section{Anti-Cytokine Therapy}

Anti-cytokine therapy here refers to blockades of cytokines, cytokine receptors, and the subsequent signaling pathways. Overexpression of some crucial pro-inflammatory cytokines, including IL-6, IL-8, and IL- $1 \beta$, was a shared phenomenon during periodontitis. These cytokines were reported to promote tumorigenesis (Kumari et al., 2016; Berraondo et al., 2019), so monoclonal antibody therapy against them or their signaling downstream molecules such as STAT3 and MAPK might help a lot (Johnson et al., 2018).

Tumor-associated macrophages (TAMs), which contribute to local tumor growth, often express some angiogenesis-promoting factors (e.g., EGFR ligands and VEGF) and immune-suppressing factors (e.g., TGF- $\beta$ and IL-10), contributing to tumor growth and metastasis. Thus, monoclonal antibody therapies targeting these molecules could relieve the tumor burden to some extent.
Inhibition of CSF1/CSF1R could suppress proliferation, differentiation, and survival of monocytes and macrophages and has been examined through multiple types of cancers (Strachan et al., 2013; Chitu and Stanley, 2017). In addition, CCR2 inhibition and PI3K inhibition, which could be used to restrict TAM recruitment into tumor sites (Okkenhaug, 2013; Le et al., 2018), might also reduce the recruitment and accumulation of TAMs into OSCC local lesions. Since TAMs tend to get accumulated inside tumor sites in OSCC patients with a smoking habit or high abundance of F. nucleatum, the strategies targeting TAMs discussed above were necessary.

\section{Adoptive Cell Therapy}

Adoptive cell therapy (ACT) is a new form of immunotherapy in which autologous immune cells (mainly $\mathrm{T}$ cells) from peripheral blood were engineered ex vivo to express tumor-specific transgenic antigen receptors such as chimeric antigen receptors (CARs) or $\mathrm{T}$ cell receptors (TCRs) (Wang and Cao, 2020). Despite the application of CD19-directed CAR-T cells having shown remarkable success in the treatment of $\mathrm{CD}^{+} 9^{+} \mathrm{B}$ cell malignancies, there are some obstacles to this method for solid tumors due to the heterogeneity of antigens expressed in solid tumors (Chan et al., 2021) and the immunosuppressive tumor microenvironment (Yeku et al., 2017). However, investigations into its solutions never stop. CAR-T cell therapy targeting ErbB family receptors has attracted a lot of interest in the treatment of head and neck cancer and was evaluated in ongoing phase I clinical trails (van Schalkwyk et al., 2013; Yeku et al., 2017). In addition, engineered $\mathrm{T}$ cells expressing the dendritic cell growth factor Flt3L were reported to overcome the clinical problem of antigen-negative tumor escape following ACT (Lai et al., 2020). Besides, many scholars demonstrate that the combination of ACT and approaches targeting immune check-point receptors would enhance anti-tumor immunity in vivo (Liu et al., 2017; Chan et al., 2021). Similarly, other therapies, such as NK cell adoptive transferring and NK cell manufacture, which have not been broadly used, might also be applied in clinical treatment in the future. In conclusion, ACT, mentioned above, has a promising future in OSCC treatment and helps solve the T cell and NK cell exhaustion in TME even though more scientific research studies are still necessary.

\section{DISCUSSION}

In this review, an abnormal immune status during the progress of OSCC was depicted first. Complete analysis of immune abnormalities caused by different oral cancer-related carcinogens was then accomplished. Based on different types of immune abnormalities induced by different carcinogens, possible individual immunotherapeutic strategies dependent on carcinogen-induced immune abnormalities were figured out as a way to possibly overcome heterogeneity of OSCC patients and enhance clinical efficacy of immunotherapies.

Nowadays, surgical resection still remains the predominant method for treatment of OSCC. However, the heavy financial and physical burden of surgical operation has become an insurmountable hurdle for lots of OSCC patients (Hamoir 
et al., 2014). In this condition, some alternative treatment methods, including immunotherapy, deserve further attempts during the treatment process of OSCC. Heterogeneity among different cancer patients acts as a main obstacle for common applications of immunotherapies among multiple cancers, OSCC included (Caswell and Swanton, 2017). Until now, multiple studies have focused on creating personalized therapies for HNSCC (Baird et al., 2018), and subgroup division seems to be an effective way for this. Until now, some subgroup division standards based on HPV status, age, and cetuximab history have failed to contribute greatly to enhancing the efficacy of immunotherapy in OSCC (Cramer et al., 2019). Different types of local immune abnormalities caused by different carcinogens suggest that subgroup division standard based on carcinogens, in combination with specific judgment of the patient immune status, might help achieve individual-targeted immunotherapy and improve the clinical outcome of immunotherapy-treated patients to a great extent.

Nevertheless, lack of systemic studies for influence of different carcinogens on the OSCC local immune status is a defect for our review, so we could only predict possible immune alternations and corresponding therapeutic strategies for OSCC. Further studies are still necessary to verify these possibilities. Besides, occurrence of OSCC depends not only on carcinogens but also genetic abnormalities, which means carcinogen-based immunotherapies might not completely explain and overcome heterogeneity of OSCC patients. In addition, a specific OSCC patient might be under the influence of more than one type of carcinogen, which might render the local immune microenvironment more complex and harder to be predicted. Multiple factor-associated OSCC has long become a challenge for

\section{REFERENCES}

Abdi, K., Chen, T., Klein, B. A., Tai, A. K., Coursen, J., Liu, X., et al. (2017). Mechanisms by Which Porphyromonas Gingivalis Evades Innate Immunity. PloS one 12, e0182164. doi:10.1371/journal.pone.0182164

Al Feghali, K. A., Ghanem, A. I., Burmeister, C., Chang, S. S., Ghanem, T., Keller, C., et al. (2019). Impact of Smoking on Pathological Features in Oral Cavity Squamous Cell Carcinoma. J. Cancer Res. Ther. 15, 582-588. doi:10.4103/jcrt.JCRT_641_16

Alexandrov, L. B., Ju, Y. S., Haase, K., Van Loo, P., Martincorena, I., Nik-Zainal, S., et al. (2016). Mutational Signatures Associated with Tobacco Smoking in Human Cancer. Science 354, 618-622. doi:10.1126/science.aag0299

Alfaro, C., Sanmamed, M. F., Rodríguez-Ruiz, M. E., Teijeira, Á., Oñate, C., González, Á., et al. (2017). Interleukin-8 in Cancer Pathogenesis, Treatment and Follow-Up. Cancer Treat. Rev. 60, 24-31. doi:10.1016/j.ctrv.2017.08.004

Andtbacka, R. H. I., Collichio, F., Harrington, K. J., Middleton, M. R., Downey, G., Öhrling, K., et al. (2019). Final Analyses of OPTiM: a Randomized Phase III Trial of Talimogene Laherparepvec versus Granulocyte-Macrophage colonystimulating Factor in Unresectable Stage III-IV Melanoma. J. Immunother. Cancer 7, 145. doi:10.1186/s40425-019-0623-z

Anguille, S., Smits, E. L., Lion, E., van Tendeloo, V. F., and Berneman, Z. N. (2014). Clinical Use of Dendritic Cells for Cancer Therapy. Lancet Oncol. 15, e257-e267. doi:10.1016/s1470-2045(13)70585-0

Ardi, V. C., Kupriyanova, T. A., Deryugina, E. I., and Quigley, J. P. (2007). Human Neutrophils Uniquely Release TIMP-free MMP-9 to Provide a Potent Catalytic Stimulator of Angiogenesis. Proc. Natl. Acad. Sci. 104, 20262-20267. doi:10.1073/pnas.0706438104

Baird, J. R., Bell, R. B., Troesch, V., Friedman, D., Bambina, S., Kramer, G., et al. (2018). Evaluation of Explant Responses to STING Ligands: Personalized chemotherapy, as different types of carcinogens would produce a complex network regulating patterns, making it an extreme dilemma for researchers. Until now, studies about OSCC chemotherapy have all focused on the influence of a single carcinogenic factor, while no such clinical study aimed at figuring out multiple factor-induced immune variations has been completed yet. Based on this research status, efforts were made in this manuscript to describe and summarize immune status variations induced by every specific OSCC carcinogen and changes of a specific immune status associated with multiple types of OSCC carcinogens. Thus, our review only aimed at a complete analysis and summarization of current knowledge about single-carcinogen-induced immune abnormalities in OSCC. Obviously, more clinical experiments focused on this issue ought to be conducted to confirm our assumption, constructing a better strategy to expand application of immunotherapies during the OSCC treatment process.

\section{AUTHOR CONTRIBUTIONS}

All authors listed have made a substantial, direct, and intellectual contribution to the work and approved it for publication.

\section{FUNDING}

This work was funded by Young Elite Scientist Sponsorship Program by CAST (2018QNRC001, to QT), and Key Supporting Program by Health Commission of Hubei Province (WJ2019C001, to LC).

Immunosurgical Therapy for Head and Neck Squamous Cell Carcinoma Cancer Res. 78, 6308-6319. doi:10.1158/0008-5472.can-18-1652

Barnes, P. J. (2016). Inflammatory Mechanisms in Patients with Chronic Obstructive Pulmonary Disease. J. Allergy Clin. Immunol. 138, 16-27. doi:10.1016/j.jaci.2016.05.011 Bazzan, E., Turato, G., Tinè, M., Radu, C. M., Balestro, E., Rigobello, C., et al. (2017). Dual Polarization of Human Alveolar Macrophages Progressively Increases with Smoking and COPD Severity. Respir. Res. 18, 40. doi:10.1186/s12931-017-0522-0

Ben-Eliyahu, S., Page, G. G., Yirmiya, R., and Taylor, A. N. (1996). Acute Alcohol Intoxication Suppresses Natural Killer Cell Activity and Promotes Tumor Metastasis. Nat. Med. 2, 457-460. doi:10.1038/nm0496-457

Bennett, S. R. M., Carbone, F. R., Karamalis, F., Flavell, R. A., Miller, J. F. A. P., and Heath, W. R. (1998). Help for Cytotoxic-T-Cell Responses Is Mediated by CD40 Signalling. Nature 393, 478-480. doi:10.1038/30996

Berlato, C., Khan, M. N., Schioppa, T., Thompson, R., Maniati, E., Montfort, A., et al. (2017). A CCR4 Antagonist Reverses the Tumor-Promoting Microenvironment of Renal Cancer. J. Clin. Invest. 127, 801-813. doi:10.1172/jci82976

Berraondo, P., Sanmamed, M. F., Ochoa, M. C., Etxeberria, I., Aznar, M. A., PérezGracia, J. L., et al. (2019). Cytokines in Clinical Cancer Immunotherapy. Br. J. Cancer 120, 6-15. doi:10.1038/s41416-018-0328-y

Bezerra, N. V., Leite, K. L., de Medeiros, M. M., Martins, M. L., Cardoso, A. M., Alves, P. M., et al. (2018). Impact of the Anatomical Location, Alcoholism and Smoking on the Prevalence of Advanced Oral Cancer in Brazil. Med. Oral Patol Oral Cir Bucal 23, e295-e301. doi:10.4317/medoral.22318

Binnewies, M., Roberts, E. W., Kersten, K., Chan, V., Fearon, D. F., Merad, M., et al. (2018). Understanding the Tumor Immune Microenvironment (TIME) for Effective Therapy. Nat. Med. 24, 541-550. doi:10.1038/s41591-018-0014-x

Blank, S. E., Duncan, D. A., and Meadows, G. G. (1991). Suppression of Natural Killer Cell Activity by Ethanol Consumption and Food Restriction. Alcohol. Clin. Exp. Res. 15, 16-22. doi:10.1111/j.1530-0277.1991.tb00514.x 
Blot, W. J., McLaughlin, J. K., Winn, D. M., Austin, D. F., Greenberg, R. S., PrestonMartin, S., et al. (1988). Smoking and Drinking in Relation to Oral and Pharyngeal Cancer. Cancer Res. 48, 3282-3287.

Boas, D. S. V., Takiya, C. M., Gurgel, C. A. S., Cabral, M. G., and Santos, J. N. d. (2013). Tumor-infiltrating Macrophage and Microvessel Density in Oral Squamous Cell Carcinoma. Braz. Dent. J. 24, 194-199. doi:10.1590/01036440201302049

Bosetti, C., Gallus, S., Franceschi, S., Levi, F., Bertuzzi, M., Negri, E., et al. (2002). Cancer of the Larynx in Non-smoking Alcohol Drinkers and in Non-drinking Tobacco Smokers. Br. J. Cancer 87, 516-518. doi:10.1038/sj.bjc.6600469

Boyadjieva, N., Advis, J. P., and Sarkar, D. K. (2006). Role of ?-Endorphin, Corticotropin-Releasing Hormone, and Autonomic Nervous System in Mediation of the Effect of Chronic Ethanol on Natural Killer Cell Cytolytic Activity. Alcohol. Clin. Exp. Res. 30, 1761-1767. doi:10.1111/j.15300277.2006.00209.x

Brunner-Weinzierl, M. C., and Rudd, C. E. (2018). CTLA-4 and PD-1 Control of T-Cell Motility and Migration: Implications for Tumor Immunotherapy. Front. Immunol. 9, 2737. doi:10.3389/fimmu.2018.02737

Campbell, L., Maxwell, P., and Waugh, D. (2013). Rationale and Means to Target Pro-inflammatory Interleukin-8 (CXCL8) Signaling in Cancer. Pharmaceuticals 6, 929-959. doi:10.3390/ph6080929

Cardoso, E. M., Reis, C., and Manzanares-Céspedes, M. C. (2018). Chronic Periodontitis, Inflammatory Cytokines, and Interrelationship with Other Chronic Diseases. Postgrad. Med. 130, 98-104. doi:10.1080/ 00325481.2018 .1396876

Casella, I., Feccia, T., Chelucci, C., Samoggia, P., Castelli, G., Guerriero, R., et al. (2003). Autocrine-paracrine VEGF Loops Potentiate the Maturation of Megakaryocytic Precursors through Flt1 Receptor. Blood 101, 1316-1323. doi:10.1182/blood-2002-07-2184

Casey, S. C., Amedei, A., Aquilano, K., Azmi, A. S., Benencia, F., Bhakta, D., et al. (2015). Cancer Prevention and Therapy through the Modulation of the Tumor Microenvironment. Semin. Cancer Biol. 35 (35 Suppl. 1), S199-s223. doi:10.1016/j.semcancer.2015.02.007

Castellsagué, X., Muñoz, N., De Stefani, E., Victora, C. G., Castelletto, R., Rolón, P. A., et al. (1999). Independent and Joint Effects of Tobacco Smoking and Alcohol Drinking on the Risk of Esophageal Cancer in Men and Women. Int. J. Cancer 82, 657-664. doi:10.1002/(sici)1097-0215(19990827)82:5<657::aid-ijc7>3.0.co; $2-\mathrm{c}$

Castellsagué, X., Quintana, M. J., Martínez, M. C., Nieto, A., Sánchez, M. J., Juan, A., et al. (2004). The Role of Type of Tobacco and Type of Alcoholic Beverage in Oral Carcinogenesis. Int. J. Cancer 108, 741-749. doi:10.1002/ijc.11627

Caswell, D. R., and Swanton, C. (2017). The Role of Tumour Heterogeneity and Clonal Cooperativity in Metastasis, Immune Evasion and Clinical Outcome,. BMC Med. 15, 133. doi:10.1186/s12916-017-0900-y

Caughron, B., Yang, Y., and Young, M. R. I. (2018). Role of IL-23 Signaling in the Progression of Premalignant Oral Lesions to Cancer. PloS one 13, e0196034. doi:10.1371/journal.pone.0196034

Chan, J. D., Lai, J., Slaney, C. Y., Kallies, A., Beavis, P. A., and Darcy, P. K. (2021). Cellular Networks Controlling T Cell Persistence in Adoptive Cell Therapy. Nat. Rev. Immunol. doi:10.1038/s41577-021-00539-6

Chang, L.-Y., Lai, Y.-L., Yu, T.-H., Chen, Y.-T., and Hung, S.-L. (2014). Effects of Areca Nut Extract on Lipopolysaccharides-Enhanced Adhesion and Migration of Human Mononuclear Leukocytes. J. Periodontol. 85, 859-867. doi:10.1902/ jop.2013.130198

Chang, L.-Y., Wan, H.-C., Lai, Y.-L., Chou, I.-C., Chen, Y.-T., and Hung, S.-L. (2013). Areca Nut Extracts Increased the Expression of Cyclooxygenase-2, Prostaglandin E2 and Interleukin-1 $a$ in Human Immune Cells via Oxidative Stress. Arch. Oral Biol. 58, 1523-1531. doi:10.1016/j.archoralbio.2013.05.006

Chang, L.-Y., Wan, H.-C., Lai, Y.-L., Kuo, Y.-F., Liu, T.-Y., Chen, Y.-T., et al. (2009). Areca Nut Extracts Increased Expression of Inflammatory Cytokines, Tumor Necrosis Factor- $\alpha$, Interleukin- $1 \beta$, Interleukin- 6 and Interleukin-8, in Peripheral Blood Mononuclear Cells. J. Periodont Res. 44, 175-183. doi:10.1111/j.1600-0765.2008.01104.x

Chang, L.-Y., Wan, H.-C., Lai, Y.-L., Liu, T.-Y., and Hung, S.-L. (2006). Enhancing Effects of Areca Nut Extracts on the Production of Interleukin-6 and Interleukin-8 by Peripheral Blood Mononuclear Cells. J. Periodontol. 77, 1969-1977. doi:10.1902/jop.2006.060039
Chaturvedi, A. K., Engels, E. A., Anderson, W. F., and Gillison, M. L. (2008). Incidence Trends for Human Papillomavirus-Related and -Unrelated Oral Squamous Cell Carcinomas in the United States. Jco 26, 612-619. doi:10.1200/jco.2007.14.1713

Chaturvedi, A. K., Graubard, B. I., Broutian, T., Pickard, R. K. L., Tong, Z.-y., Xiao, W., et al. (2015). NHANES 2009-2012 Findings: Association of Sexual Behaviors with Higher Prevalence of Oral Oncogenic Human Papillomavirus Infections in U.S. Men. Cancer Res. 75, 2468-2477. doi:10.1158/0008-5472.can-14-2843

Chen, C. P., Boyadjieva, N. I., Advis, J. P., and Sarkar, D. K. (2006). Ethanol Suppression of the Hypothalamic Proopiomelanocortin Level and the Splenic NK Cell Cytolytic Activity Is Associated with a Reduction in the Expression of Proinflammatory Cytokines but Not Anti-inflammatory Cytokines in Neuroendocrine and Immune Cells. Alcohol. Clin. Exp. Res. 30, 1925-1932. doi:10.1111/j.1530-0277.2006.00237.x

Chen, H., Liakou, C. I., Kamat, A., Pettaway, C., Ward, J. F., Tang, D. N., et al. (2009). Anti-CTLA-4 Therapy Results in Higher CD4+ICOShiT Cell Frequency and IFN- $\gamma$ Levels in Both Nonmalignant and Malignant Prostate Tissues. Pnas 106, 2729-2734. doi:10.1073/pnas.0813175106

Chen, L., Fan, J., Chen, H., Meng, Z., Chen, Z., Wang, P., et al. (2014). The IL-8/ CXCR1 axis Is Associated with Cancer Stem Cell-like Properties and Correlates with Clinical Prognosis in Human Pancreatic Cancer Cases,. Scientific Rep. 4, 5911. doi:10.1038/srep05911

Chen, T., Li, Q., Wu, J., Wu, Y., Peng, W., Li, H., et al. (2018). Fusobacterium Nucleatum Promotes M2 Polarization of Macrophages in the Microenvironment of Colorectal Tumours via a TLR4-dependent Mechanism. Cancer Immunol. Immunother. 67, 1635-1646. doi:10.1007/ s00262-018-2233-x

Cheng, Y. A., Shiue, L. F., Yu, H. S., Hsieh, T. Y., and Tsai, C. C. (2000). Interleukin8 Secretion by Cultured Oral Epidermoid Carcinoma Cells Induced with Nicotine And/or Arecoline Treatments. Kaohsiung J. Med. Sci. 16, 126-133.

Chi, N., Tan, Z., Ma, K., Bao, L., and Yun, Z. (2014). Increased Circulating MyeloidDerived Suppressor Cells Correlate with Cancer Stages, Interleukin-8 and -6 in Prostate Cancer. Int. J. Clin. Exp. Med. 7, 3181-3192.

Chitu, V., and Stanley, E. R. (2017). Regulation of Embryonic and Postnatal Development by the CSF-1 Receptor. Curr. Top. Dev. Biol. 123, 229-275. doi:10.1016/bs.ctdb.2016.10.004

Cho, E., Smith-Warner, S. A., Ritz, J., van den Brandt, P. A., Colditz, G. A., Folsom, A. R., et al. (2004). Alcohol Intake and Colorectal Cancer: a Pooled Analysis of 8 Cohort Studies. Ann. Intern. Med. 140, 603-613. doi:10.7326/0003-4819-140-8200404200-00007

Chow, L. Q. M. (2020). Head and Neck Cancer. N. Engl. J. Med. 382, 60-72. doi:10.1056/NEJMra1715715

Constantino, J., Gomes, C., Falcão, A., Neves, B. M., and Cruz, M. T. (2017). Dendritic Cell-Based Immunotherapy: a Basic Review and Recent Advances. Immunol. Res. 65, 798-810. doi:10.1007/s12026-017-8931-1

Cozen, W., Diaz-Sanchez, D., James Gauderman, W., Zadnick, J., Cockburn, M. G., Gill, P. S., et al. (2004). Th1 and Th2 Cytokines and IgE Levels in Identical Twins with Varying Levels of Cigarette Consumption. J. Clin. Immunol. 24, 617-622. doi:10.1007/s10875-004-6247-0

Cramer, J. D., Burtness, B., and Ferris, R. L. (2019). Immunotherapy for Head and Neck Cancer: Recent Advances and Future Directions. Oral Oncol. 99, 104460. doi:10.1016/j.oraloncology.2019.104460

Daley, D., Mani, V. R., Mohan, N., Akkad, N., Pandian, G. S. D. B., Savadkar, S., et al. (2017). NLRP3 Signaling Drives Macrophage-Induced Adaptive Immune Suppression in Pancreatic Carcinoma. J. Exp. Med. 214, 1711-1724. doi:10.1084/jem.20161707

Dar, A. A., Patil, R. S., Pradhan, T. N., Chaukar, D. A., D'Cruz, A. K., and Chiplunkar, S. V. (2020). Myeloid-derived Suppressor Cells Impede T Cell Functionality and Promote Th17 Differentiation in Oral Squamous Cell Carcinoma, Cancer Immunology, Immunotherapy. Cancer Immunol. Immunother. 69, 1071-1086. doi:10.1007/s00262-020-02523-w

Das, A., Monteiro, M., Barai, A., Kumar, S., and Sen, S. (2017). MMP Proteolytic Activity Regulates Cancer Invasiveness by Modulating Integrins. Scientific Rep. 7, 14219. doi:10.1038/s41598-017-14340-w

Dasgupta, R., Saha, I., Pal, S., Bhattacharyya, A., Sa, G., Nag, T. C., et al. (2006). Immunosuppression, Hepatotoxicity and Depression of Antioxidant Status by 
Arecoline in Albino Mice. Toxicology 227, 94-104. doi:10.1016/ j.tox.2006.07.016

Dave, K., Ali, A., and Magalhaes, M. (2020). Increased Expression of PD-1 and PDL1 in Oral Lesions Progressing to Oral Squamous Cell Carcinoma: a Pilot Study. Sci. Rep. 10, 9705. doi:10.1038/s41598-020-66257-6

David, J. M., Dominguez, C., Hamilton, D. H., and Palena, C. (2016). The IL-8/IL8R Axis: A Double Agent in Tumor Immune Resistance,. Vaccines 4, 22. doi: $10.3390 /$ vaccines 4030022

De Costa, A.-M. A., Schuyler, C. A., Walker, D. D., and Young, M. R. I. (2012). Characterization of the Evolution of Immune Phenotype during the Development and Progression of Squamous Cell Carcinoma of the Head and Neck. Cancer Immunol. Immunother. 61, 927-939. doi:10.1007/s00262011-1154-8

de la Iglesia, J. V., Slebos, R. J. C., Martin-Gomez, L., Wang, X., Teer, J. K., Tan, A. C., et al. (2020). Effects of Tobacco Smoking on the Tumor Immune Microenvironment in Head and Neck Squamous Cell Carcinoma. Clin. Cancer Res. 26, 1474-1485. doi:10.1158/1078-0432.ccr-19-1769

Dempke, W. C. M., Fenchel, K., Uciechowski, P., and Dale, S. P. (2017). Secondand Third-Generation Drugs for Immuno-Oncology Treatment-The More the Better? Eur. J. Cancer 74, 55-72. doi:10.1016/j.ejca.2017.01.001

Ding, S., Tang, Z., Jiang, Y., Huang, H., Luo, P., Qing, B., et al. (2017). IL-8 Is Involved in Estrogen-Related Receptor $\alpha$-Regulated Proliferation and Migration of Colorectal Cancer Cells. Dig. Dis. Sci. 62, 3438-3446. doi:10.1007/s10620-017-4779-4

Dong, H., Strome, S. E., Salomao, D. R., Tamura, H., Hirano, F., Flies, D. B., et al. (2002). Tumor-associated B7-H1 Promotes T-Cell Apoptosis: a Potential Mechanism of Immune Evasion. Nat. Med. 8, 793-800. doi:10.1038/nm730

Dutta, A., Banerjee, A., Saikia, N., Phookan, J., Baruah, M. N., and Baruah, S. (2015). Negative Regulation of Natural Killer Cell in Tumor Tissue and Peripheral Blood of Oral Squamous Cell Carcinoma. Cytokine 76, 123-130. doi:10.1016/j.cyto.2015.09.006

Egberts, J.-H., Cloosters, V., Noack, A., Schniewind, B., Thon, L., Klose, S., et al. (2008). Anti-tumor Necrosis Factor Therapy Inhibits Pancreatic Tumor Growth and Metastasis. Cancer Res. 68, 1443-1450. doi:10.1158/00085472.can-07-5704

Einstein, M. H., Leanza, S., Chiu, L. G., Schlecht, N. F., Goldberg, G. L., Steinberg, B. M., et al. (2009). Genetic Variants in TAP Are Associated with High-Grade Cervical Neoplasia. Clin. Cancer Res. 15, 1019-1023. doi:10.1158/10780432.ccr-08-1207

Emmerich, J., Mumm, J. B., Chan, I. H., LaFace, D., Truong, H., McClanahan, T., et al. (2012). IL-10 Directly Activates and Expands Tumor-Resident CD8+ $\mathrm{T}$ Cells without De Novo Infiltration from Secondary Lymphoid Organs. Cancer Res. 72, 3570-3581. doi:10.1158/0008-5472.can-12-0721

Essa, A. A. M., Yamazaki, M., Maruyama, S., Abé, T., Babkair, H., Raghib, A. M., et al. (2016). Tumour-associated Macrophages Are Recruited and Differentiated in the Neoplastic Stroma of Oral Squamous Cell Carcinoma. Pathology 48, 219-227. doi:10.1016/j.pathol.2016.02.006

Facchinetti, F., Amadei, F., Geppetti, P., Tarantini, F., Di Serio, C., Dragotto, A., et al. (2007). $\alpha, \beta$-Unsaturated Aldehydes in Cigarette Smoke Release Inflammatory Mediators from Human Macrophages. Am. J. Respir. Cel Mol Biol 37, 617-623. doi:10.1165/rcmb.2007-0130oc

Faouzi, M., Neupane, R. P., Yang, J., Williams, P., and Penner, R. (2018). Areca Nut Extracts Mobilize Calcium and Release Pro-inflammatory Cytokines from Various Immune Cells. Sci. Rep. 8, 1075. doi:10.1038/s41598-017-18996-2

Farhood, B., Najafi, M., and Mortezaee, K. (2019). CD8 + Cytotoxic T Lymphocytes in Cancer Immunotherapy: A Review. J. Cel Physiol 234, 8509-8521. doi:10.1002/jcp. 27782

Feng, B., Shen, Y., Pastor, X., Bieg, M., Plath, M., Ishaque, N., et al. (2020). Integrative Analysis of Multi-Omics Data Identified EGFR and PTGS2 as Key Nodes in a Gene Regulatory Network Related to Immune Phenotypes in Head and Neck Cancer. Clin. Cancer Res. 26, 3616-3628. doi:10.1158/10780432.CCR-19-3997

Ferris, R. L., Blumenschein, G., Jr., Fayette, J., Guigay, J., Colevas, A. D., Licitra, L., et al. (2016). Nivolumab for Recurrent Squamous-Cell Carcinoma of the Head and Neck. N. Engl. J. Med. 375, 1856-1867. doi:10.1056/nejmoa1602252

Floros, T., and Tarhini, A. A. (2015). Anticancer Cytokines: Biology and Clinical Effects of Interferon-A2, Interleukin (IL)-2, IL-15, IL-21, and IL-12. Semin. Oncol. 42, 539-548. doi:10.1053/j.seminoncol.2015.05.015
Foulds, K. E., Rotte, M. J., and Seder, R. A. (2006). IL-10 Is Required for Optimal CD8 T Cell Memory followingListeria monocytogenesInfection. J. Immunol. 177, 2565-2574. doi:10.4049/jimmunol.177.4.2565

Gabrilovich, D. I. (2017). Myeloid-Derived Suppressor Cells. Cancer Immunol. Res. 5, 3-8. doi:10.1158/2326-6066.cir-16-0297

Gabrilovich, D. I., Ostrand-Rosenberg, S., and Bronte, V. (2012). Coordinated Regulation of Myeloid Cells by Tumours. Nat. Rev. Immunol. 12, 253-268. doi:10.1038/nri3175

Galvis, M. M., Borges, G. A., Oliveira, T. B. d., Toledo, I. P. d., Castilho, R. M., Guerra, E. N. S., et al. (2020). Immunotherapy Improves Efficacy and Safety of Patients with HPV Positive and Negative Head and Neck Cancer: A Systematic Review and Meta-Analysis. Crit. Rev. oncology/hematology 150, 102966. doi:10.1016/j.critrevonc.2020.102966

Gameiro, S. F., Ghasemi, F., Barrett, J. W., Koropatnick, J., Nichols, A. C., Mymryk, J. S., et al. (2018). Treatment-naïve HPV+ Head and Neck Cancers Display a T-Cell-Inflamed Phenotype Distinct from Their HPV-Counterparts that Has Implications for Immunotherapy. Oncoimmunology 7, e1498439. doi:10.1080/ 2162402x.2018.1498439

Gao, Y., Zhou, Z., Ren, T., Kim, S.-J., He, Y., Seo, W., et al. (2019). Alcohol Inhibits T-Cell Glucose Metabolism and Hepatitis in ALDH2-Deficient Mice and Humans: Roles of Acetaldehyde and Glucocorticoids. Gut 68, 1311-1322. doi:10.1136/gutjnl-2018-316221

Gardner, A., Ruffell, B., Cells, Dendritic., and Immunity, Cancer. (2016). Dendritic Cells and Cancer Immunity. Trends Immunology 37, 855-865. doi:10.1016/ j.it.2016.09.006

Gaur, P., Singh, A. K., Shukla, N. K., and Das, S. N. (2014). Inter-relation of Th1, Th2, Th17 and Treg Cytokines in Oral Cancer Patients and Their Clinical Significance. Hum. Immunol. 75, 330-337. doi:10.1016/j.humimm.2014.01.011

Ghanizada, M., Jakobsen, K. K., Grønhøj, C., and von Buchwald, C. (2019). The Effects of Checkpoint Inhibition on Head and Neck Squamous Cell Carcinoma: A Systematic Review. Oral Oncol. 90, 67-73. doi:10.1016/ j.oraloncology.2019.01.018

Giese, M. A., Hind, L. E., and Huttenlocher, A. (2019). Neutrophil Plasticity in the Tumor Microenvironment. Blood 133, 2159-2167. doi:10.1182/blood-2018-11844548

Goodman, A., Patel, S. P., and Kurzrock, R. (2017). PD-1-PD-L1 ImmuneCheckpoint Blockade in B-Cell Lymphomas. Nat. Rev. Clin. Oncol. 14, 203-220. doi:10.1038/nrclinonc.2016.168

Granero Fernandez, M., and Lopez-Jornet, P. (2017). Association between Smoking, Glycaemia, Blood Lipoproteins and Risk of Oral Leukoplakia. Aust. Dent J. 62, 47-51. doi:10.1111/adj.12431

Granot, Z., Henke, E., Comen, E. A., King, T. A., Norton, L., and Benezra, R. (2011). Tumor Entrained Neutrophils Inhibit Seeding in the Premetastatic Lung. Cancer cell 20, 300-314. doi:10.1016/j.ccr.2011.08.012

Greene, S., Robbins, Y., Mydlarz, W. K., Huynh, A. P., Schmitt, N. C., Friedman, J., et al. (2020). Inhibition of MDSC Trafficking with SX-682, a CXCR1/2 Inhibitor, Enhances NK-Cell Immunotherapy in Head and Neck Cancer Models. Clin. Cancer Res. 26, 1420-1431. doi:10.1158/1078-0432.ccr-19-2625 Guillerey, C., Huntington, N. D., and Smyth, M. J. (2016). Targeting Natural Killer Cells in Cancer Immunotherapy. Nat. Immunol. 17, 1025-1036. doi:10.1038/ni.3518

Güngör, N., Knaapen, A. M., Munnia, A., Peluso, M., Haenen, G. R., Chiu, R. K., et al. (2010). Genotoxic Effects of Neutrophils and Hypochlorous Acid. Mutagenesis 25, 149-154. doi:10.1093/mutage/gep053

Gur, C., Ibrahim, Y., Isaacson, B., Yamin, R., Abed, J., Gamliel, M., et al. (2015). Binding of the Fap2 Protein of Fusobacterium Nucleatum to Human Inhibitory Receptor TIGIT Protects Tumors from Immune Cell Attack. Immunity 42, 344-355. doi:10.1016/j.immuni.2015.01.010

Ha, N. H., Park, D. G., Woo, B. H., Kim, D. J., Choi, J. I., Park, B. S., et al. (2016). Porphyromonas Gingivalis Increases the Invasiveness of Oral Cancer Cells by Upregulating IL-8 and MMPs. Cytokine 86, 64-72. doi:10.1016/j.cyto.2016.07.013

Hajishengallis, G. (2015). Periodontitis: from Microbial Immune Subversion to Systemic Inflammation. Nat. Rev. Immunol. 15, 30-44. doi:10.1038/nri3785

Hamoir, M., Schmitz, S., and Gregoire, V. (2014). The Role of Neck Dissection in Squamous Cell Carcinoma of the Head and Neck. Curr. Treat. Options. Oncol. 15, 611-624. doi:10.1007/s11864-014-0311-7

Hanakawa, H., Orita, Y., Sato, Y., Takeuchi, M., Ohno, K., Gion, Y., et al. (2014). Regulatory T-Cell Infiltration in Tongue Squamous Cell Carcinoma. Acta otolaryngologica 134, 859-864. doi:10.3109/00016489.2014.918279 
Hanazawa, A., Ito, R., Katano, I., Kawai, K., Goto, M., Suemizu, H., et al. (2018). Generation of Human Immunosuppressive Myeloid Cell Populations in Human Interleukin-6 Transgenic NOG Mice. Front. Immunol. 9, 152. doi:10.3389/fimmu.2018.00152

Hashibe, M., Li, Q., Chen, C.-J., Hsu, W.-L., Lou, P.-J., Zhu, C., et al. (2019). Involuntary Smoking and the Risk of Head and Neck Cancer in an East Asian Population. Cancer Epidemiol. 59, 173-177. doi:10.1016/j.canep.2019.01.020

He, Q.-F., Xu, Y., Li, J., Huang, Z.-M., Li, X.-H., and Wang, X. (2019). CD8+ T-Cell Exhaustion in Cancer: Mechanisms and New Area for Cancer Immunotherapy. Brief. Funct. genomics 18, 99-106. doi:10.1093/bfgp/ely006

Hodge, S., Hodge, G., Scicchitano, R., Reynolds, P. N., and Holmes, M. (2003). Alveolar Macrophages from Subjects with Chronic Obstructive Pulmonary Disease Are Deficient in Their Ability to Phagocytose Apoptotic Airway Epithelial Cells. Immunol. Cel Biol 81, 289-296. doi:10.1046/j.14401711.2003.t01-1-01170.x

Holway, G. V., and Hernandez, S. M. (2018). Oral Sex and Condom Use in a U.S. National Sample of Adolescents and Young Adults. J. Adolesc. Health 62, 402-410. doi:10.1016/j.jadohealth.2017.08.022

Horiuchi, Y., Tominaga, M., Ichikawa, M., Yamashita, M., Okano, K., Jikumaru, Y., et al. (2010). Relationship between Regulatory and Type $1 \mathrm{~T}$ Cells in Dogs with Oral Malignant Melanoma. Microbiol. Immunol. 54, 152-159. doi:10.1111/ j.1348-0421.2009.00194.x

Hosseini, A., Gharibi, T., Marofi, F., Babaloo, Z., and Baradaran, B. (2020). CTLA4: From Mechanism to Autoimmune Therapy. Int. Immunopharmacology 80, 106221. doi:10.1016/j.intimp.2020.106221

Hu, Y. J., Chen, J., Zhong, W. S., Ling, T. Y., Jian, X. C., Lu, R. H., et al. (2017). Trend Analysis of Betel Nut-associated Oral Cancer and Health Burden in China. Chin. J. Dent Res. 20, 69-78. doi:10.3290/j.cjdr.a38271

Huang, D., Song, S.-J., Wu, Z.-Z., Wu, W., Cui, X.-Y., Chen, J.-N., et al. (2017). Epstein-Barr Virus-Induced VEGF and GM-CSF Drive Nasopharyngeal Carcinoma Metastasis via Recruitment and Activation of Macrophages. Cancer Res. 77, 3591-3604. doi:10.1158/0008-5472.can-16-2706

Huang, M.-F., Lin, W.-L., and Ma, Y.-C. (2005). A Study of Reactive Oxygen Species in Mainstream of Cigarette. Indoor air 15, 135-140. doi:10.1111/j.16000668.2005.00330.x

Huang, W., Chen, Z., Zhang, L., Tian, D., Wang, D., Fan, D., et al. (2015). Interleukin-8 Induces Expression of FOXC1 to Promote Transactivation of CXCR1 and CCL2 in Hepatocellular Carcinoma Cell Lines and Formation of Metastases in Mice. Gastroenterology 149, 1053-1067. e1014. doi:10.1053/ j.gastro.2015.05.058

Huang, Z., Xie, N., Liu, H., Wan, Y., Zhu, Y., Zhang, M., et al. (2019). The Prognostic Role of Tumour-infiltrating Lymphocytes in Oral Squamous Cell Carcinoma: A Meta-analysis. J. Oral Pathol. Med. 48, 788-798. doi:10.1111/ jop. 12927

Hung, S.-L., Lee, Y.-Y., Liu, T.-Y., Peng, J.-L., Cheng, Y.-Y., and Chen, Y.-T. (2006). Modulation of Phagocytosis, Chemotaxis, and Adhesion of Neutrophils by Areca Nut Extracts. J. Periodontol. 77, 579-585. doi:10.1902/jop.2006.050217

Hunt, J. D., Robert, E. G., Zieske, A. W., Bautista, A. P., Bukara, M., Lei, D., et al. (2000). Orthotopic Human Lung Carcinoma Xenografts in BALB/c Mice Immunosuppressed with Anti-CD4 Monoclonal Antibodies and Chronic Alcohol Consumption. Cancer 88, 468-479. doi:10.1002/(sici)10970142(20000115)88:2<468::aid-cncr30>3.0.co;2-\#

Im, H.-J., Kim, H.-G., Lee, J.-S., Kim, H.-S., Cho, J.-H., Jo, I.-J., et al. (2016). A Preclinical Model of Chronic Alcohol Consumption Reveals Increased Metastatic Seeding of Colon Cancer Cells in the Liver. Cancer Res. 76, 1698-1704. doi:10.1158/0008-5472.can-15-2114

Irimie, A. I., Braicu, C., Pileczki, V., Petrushev, B., Soritau, O., Campian, R. S., et al. (2016). Knocking Down of P53 Triggers Apoptosis and Autophagy, Concomitantly with Inhibition of Migration on SSC-4 Oral Squamous Carcinoma Cells. Mol. Cel Biochem 419, 75-82. doi:10.1007/s11010-016-2751-9

Jauregui, C. E., Wang, Q., Wright, C. J., Takeuchi, H., Uriarte, S. M., and Lamont, R. J. (2013). Suppression of T-Cell Chemokines by Porphyromonas Gingivalis. Infect. Immun. 81, 2288-2295. doi:10.1128/iai.00264-13

Jelski, W., Kozlowski, M., Laudanski, J., Niklinski, J., and Szmitkowski, M. (2009). Alcohol Dehydrogenase Isoenzymes and Aldehyde Dehydrogenase Activity in the Sera of Patients with Esophageal Cancer. Clin. Exp. Med. 9, 131-137. doi:10.1007/s10238-008-0028-7
Jeng, J.-H., Wang, Y.-J., Chiang, B.-L., Lee, P.-H., Chan, C.-P., Ho, Y.-S., et al. (2003). Roles of Keratinocyte Inflammation in Oral Cancer: Regulating the Prostaglandin E2, Interleukin-6 and TNF- Production of Oral Epithelial Cells by Areca Nut Extract and Arecoline. Carcinogenesis 24, 1301-1315. doi:10.1093/carcin/bgg083

Jeng, J. H., Ho, Y. S., Chan, C. P., Wang, Y. J., Hahn, L. J., Lei, D., et al. (2000). Areca Nut Extract Up-Regulates Prostaglandin Production, Cyclooxygenase-2 mRNA and Protein Expression of Human Oral Keratinocytes. Carcinogenesis 21, 1365-1370. doi:10.1093/carcin/21.5.365

Jeong, W. I., Park, O., and Gao, B. (2008). Abrogation of the Antifibrotic Effects of Natural Killer Cells/Interferon- $\gamma$ Contributes to Alcohol Acceleration of Liver Fibrosis. Gastroenterology 134, 248-258. doi:10.1053/j.gastro.2007.09.034

Jiun, I. L., Siddik, S. N., Malik, S. N., Tin-Oo, M. M., Alam, M. K., Khan, M. M., et al. (2015). Association between Oral Hygiene Status and Halitosis Among Smokers and Nonsmokers. Oral Health Prev. Dent 13, 395-405. doi:10.3290/ j.ohpd.a33920

Johnson, D. E., O'Keefe, R. A., and Grandis, J. R. (2018). Targeting the IL-6/JAK/ STAT3 Signalling axis in Cancer. Nat. Rev. Clin. Oncol. 15, 234-248. doi: $10.1038 /$ nrclinonc. 2018.8

Johnston, R. J., Comps-Agrar, L., Hackney, J., Yu, X., Huseni, M., Yang, Y., et al. (2014). The Immunoreceptor TIGIT Regulates Antitumor and Antiviral CD8 + T Cell Effector Function. Cancer Cell 26, 923-937. doi:10.1016/j.ccell.2014.10.018

Joyce, J. A., and Pollard, J. W. (2009). Microenvironmental Regulation of Metastasis. Nat. Rev. Cancer 9, 239-252. doi:10.1038/nrc2618

Kabat, G. C., and Wynder, E. L. (1989). Type of Alcoholic Beverage and Oral Cancer. Int. J. Cancer 43, 190-194. doi:10.1002/ijc.2910430203

Kagohara, L. T., Zamuner, F., Davis-Marcisak, E. F., Sharma, G., Considine, M., Allen, J., et al. (2020). Integrated Single-Cell and Bulk Gene Expression and ATAC-Seq Reveals Heterogeneity and Early Changes in Pathways Associated with Resistance to Cetuximab in HNSCC-Sensitive Cell Lines. Br. J. Cancer 123 101-113. doi:10.1038/s41416-020-0851-5

Kansy, B. A., Concha-Benavente, F., Srivastava, R. M., Jie, H.-B., Shayan, G., Lei, Y., et al. (2017). PD-1 Status in CD8+ T Cells Associates with Survival and AntiPD-1 Therapeutic Outcomes in Head and Neck Cancer. Cancer Res. 77, 6353-6364. doi:10.1158/0008-5472.can-16-3167

Kato, T., Noma, K., Ohara, T., Kashima, H., Katsura, Y., Sato, H., et al. (2018). Cancer-Associated Fibroblasts Affect Intratumoral CD8+ and FoxP3+ T Cells via IL6 in the Tumor Microenvironment. Clin. Cancer Res. 24, 4820-4833. doi:10.1158/1078-0432.ccr-18-0205

Katz, P. S., Siggins, R. W., Porretta, C., Armstrong, M. L., Zea, A. H., Mercante, D. E., et al. (2015). Chronic Alcohol Increases CD8+ T-Cell Immunosenescence in Simian Immunodeficiency Virus-Infected Rhesus Macaques. Alcohol 49, 759-765. doi:10.1016/j.alcohol.2015.09.003

Kennedy, L. B., and Salama, A. K. S. (2020). A Review of Cancer Immunotherapy Toxicity,. CA Cancer J. Clin. 70. doi:10.3322/caac.21596

Khalaf, H., and Bengtsson, T. (2012). Altered T-Cell Responses by the Periodontal Pathogen Porphyromonas Gingivalis. PloS one 7, e45192. doi:10.1371/ journal.pone.0045192

Kinane, D. F., Stathopoulou, P. G., and Papapanou, P. N. (2017). Periodontal Diseases, Nature Reviews. Dis. primers 3, 17038. doi:10.1038/nrdp.2017.38

Kirkham, P. A., Spooner, G., Rahman, I., and Rossi, A. G. (2004). Macrophage Phagocytosis of Apoptotic Neutrophils Is Compromised by Matrix Proteins Modified by Cigarette Smoke and Lipid Peroxidation Products. Biochem. biophysical Res. Commun. 318, 32-37. doi:10.1016/j.bbrc.2004.04.003

Koehn, B. H., Apostolova, P., Haverkamp, J. M., Miller, J. S., McCullar, V., Tolar, J., et al. (2015). GVHD-associated, Inflammasome-Mediated Loss of Function in Adoptively Transferred Myeloid-Derived Suppressor Cells. Blood 126, 1621-1628. doi:10.1182/blood-2015-03-634691

Korc, M., Jeon, C. Y., Edderkaoui, M., Pandol, S. J., and Petrov, M. S. (2017). Tobacco and Alcohol as Risk Factors for Pancreatic Cancer. Best Pract. Res. Clin. Gastroenterol. 31, 529-536. doi:10.1016/j.bpg.2017.09.001

Kostic, A. D., Chun, E., Robertson, L., Glickman, J. N., Gallini, C. A., Michaud, M., et al. (2013). Fusobacterium Nucleatum Potentiates Intestinal Tumorigenesis and Modulates the Tumor-Immune Microenvironment. Cell Host \& Microbe 14, 207-215. doi:10.1016/j.chom.2013.07.007

Kotani, N., Hashimoto, H., Sessler, D. I., Yoshida, H., Kimura, N., Okawa, H., et al. (2000). Smoking Decreases Alveolar Macrophage Function during Anesthesia and Surgery. Anesthesiology 92, 1268-1277. doi:10.1097/00000542-200005000-00014 
Kouketsu, A., Sato, I., Oikawa, M., Shimizu, Y., Saito, H., Tashiro, K., et al. (2019). Regulatory T Cells and M2-Polarized Tumour-Associated Macrophages Are Associated with the Oncogenesis and Progression of Oral Squamous Cell Carcinoma. Int. J. Oral Maxill. Surg. 48, 1279-1288. doi:10.1016/ j.ijom.2019.04.004

Krishna, S., Ulrich, P., Wilson, E., Parikh, F., Narang, P., Yang, S., et al. (2018). Human Papilloma Virus Specific Immunogenicity and Dysfunction of CD8+ T Cells in Head and Neck Cancer. Cancer Res. 78, 6159-6170. doi:10.1158/ 0008-5472.can-18-0163

Kroening, P. R., Barnes, T. W., Pease, L., Limper, A., Kita, H., and Vassallo, R. (2008). Cigarette Smoke-Induced Oxidative Stress Suppresses Generation of Dendritic Cell IL-12 and IL-23 through ERK-dependent Pathways. J. Immunol. 181, 1536-1547. doi:10.4049/jimmunol.181.2.1536

Kumar, M., Nanavati, R., Modi, T., and Dobariya, C. (2016). Oral Cancer: Etiology and Risk Factors: A Review. J. Can. Res. Ther. 12, 458-463. doi:10.4103/0973-1482.186696

Kumar, S., Torres, M. P., Kaur, S., Rachagani, S., Joshi, S., Johansson, S. L., et al. (2015). Smoking Accelerates Pancreatic Cancer Progression by Promoting Differentiation of MDSCs and Inducing HB-EGF Expression in Macrophages. Oncogene 34, 2052-2060. doi:10.1038/onc.2014.154

Kumari, N., Dwarakanath, B. S., Das, A., and Bhatt, A. N. (2016). Role of Interleukin-6 in Cancer Progression and Therapeutic Resistance. Tumor Biol. 37, 11553-11572. doi:10.1007/s13277-016-5098-7

Lai, J., Mardiana, S., House, I. G., Sek, K., Henderson, M. A., Giuffrida, L., et al. (2020). Adoptive Cellular Therapy with T Cells Expressing the Dendritic Cell Growth Factor Flt3L Drives Epitope Spreading and Antitumor Immunity. Nat. Immunol. 21, 914-926. doi:10.1038/s41590-020-0676-7

Lauerova, L., Dusek, L., Simickova, M., Kocák, I., Vagundová, M., Zaloudík, J., et al. (2002). Malignant Melanoma Associates with Th1/Th2 Imbalance that Coincides with Disease Progression and Immunotherapy Response. Neoplasma 49, 159-166.

Lauw, F. N., Pajkrt, D., Hack, C. E., Kurimoto, M., van Deventer, S. J. H., and van der Poll, T. (2000). Proinflammatory Effects of IL-10 during Human Endotoxemia. J. Immunol. 165, 2783-2789. doi:10.4049/jimmunol.165.5.2783

Le, D., Gutierrez, M. E., Saleh, M., Chen, E., Mallick, A. B., Pishvaian, M. J., et al. (2018). Abstract CT124: A Phase Ib/II Study of BMS-813160, a CC Chemokine Receptor (CCR) 2/5 Dual Antagonist, in Combination with Chemotherapy or Nivolumab in Patients (Pts) with Advanced Pancreatic or Colorectal Cancer,. Cancer Res. 78, CT124. doi:10.1158/1538-7445.AM2018-CT124

Lechien, J. R., Seminerio, I., Descamps, G., Mat, Q., Mouawad, F., Hans, S., et al. (2019). Impact of HPV Infection on the Immune System in Oropharyngeal and Non-oropharyngeal Squamous Cell Carcinoma: A Systematic Review,. Cells 8. doi:10.3390/cells8091061

Lee, C.-H., Liu, S.-Y., Chou, K.-C., Yeh, C.-T., Shiah, S.-G., Huang, R.-Y., et al. (2014). Tumor-associated Macrophages Promote Oral Cancer Progression through Activation of the Axl Signaling Pathway. Ann. Surg. Oncol. 21, 1031-1037. doi:10.1245/s10434-013-3400-0

Lee, J.-J., Kao, K.-C., Chiu, Y.-L., Jung, C.-J., Liu, C.-J., Cheng, S.-J., et al. (2017). Enrichment of Human CCR6+ Regulatory T Cells with Superior Suppressive Activity in Oral Cancer. J.I. 199, 467-476. doi:10.4049/jimmunol.1601815

Lee, M.-H., Tung-Chieh Chang, J., Liao, C.-T., Chen, Y.-S., Kuo, M.-L., and Shen, C.-R. (2018). Interleukin 17 and Peripheral IL-17-expressing T Cells Are Negatively Correlated with the Overall Survival of Head and Neck Cancer Patients. Oncotarget 9, 9825-9837. doi:10.18632/oncotarget.23934

Lee, Y., Awasthi, A., Yosef, N., Quintana, F. J., Xiao, S., Peters, A., et al. (2012). Induction and Molecular Signature of Pathogenic TH17 Cells. Nat. Immunol. 13, 991-999. doi:10.1038/ni.2416

Lertpimonchai, A., Rattanasiri, S., Arj-Ong Vallibhakara, S., Attia, J., and Thakkinstian, A. (2017). The Association between Oral hygiene and Periodontitis: a Systematic Review and Meta-Analysis. Int. dental J. 67, 332-343. doi:10.1111/idj.12317

Li, B., Ren, M., Zhou, X., Han, Q., and Cheng, L. (2020). Targeting TumorAssociated Macrophages in Head and Neck Squamous Cell Carcinoma. Oral Oncol. 106, 104723. doi:10.1016/j.oraloncology.2020.104723

Li, C., Zhang, N., Zhou, J., Ding, C., Jin, Y., Cui, X., et al. (2018). Peptide Blocking of PD-1/pd-L1 Interaction for Cancer Immunotherapy. Cancer Immunol. Res. 6, 178-188. doi:10.1158/2326-6066.cir-17-0035

Li, H., Edin, M. L., Gruzdev, A., Cheng, J., Bradbury, J. A., Graves, J. P., et al. (2013). Regulation of T Helper Cell Subsets by Cyclooxygenases and Their Metabolites.
Prostaglandins \& Other Lipid Mediators 104-105, 74-83. doi:10.1016/ j.prostaglandins.2012.11.002

Li, X., Xu, Q., Wu, Y., Li, J., Tang, D., Han, L., et al. (2014). A CCL2/ROS Autoregulation Loop Is Critical for Cancer-Associated Fibroblasts-Enhanced Tumor Growth of Oral Squamous Cell Carcinoma. Carcinogenesis 35, 1362-1370. doi:10.1093/carcin/bgu046

Li, Y.-C., Chang, J. T., Chiu, C., Lu, Y.-C., Li, Y.-L., Chiang, C.-H., et al. (2016). Areca Nut Contributes to Oral Malignancy through Facilitating the Conversion of Cancer Stem Cells. Mol. Carcinog. 55, 1012-1023. doi:10.1002/mc.22344

Lien, M.-Y., Lin, C.-W., Tsai, H.-C., Chen, Y.-T., Tsai, M.-H., Hua, C.-H., et al. (2017). Impact of CCL4 Gene Polymorphisms and Environmental Factors on Oral Cancer Development and Clinical Characteristics. Oncotarget 8, 31424-31434. doi:10.18632/oncotarget.15615

Lien, M. Y., Tsai, H. C., Chang, A. C., Tsai, M. H., Hua, C. H., Wang, S. W., et al. (2018). Chemokine CCL4 Induces Vascular Endothelial Growth Factor C Expression and Lymphangiogenesis by miR-195-3p in Oral Squamous Cell Carcinoma. Front. Immunol. 9, 412. doi:10.3389/fimmu.2018.00412

Lim, K. P., Chun, N. A., Ismail, S. M., Abraham, M. T., Yusoff, M. N., Zain, R. B., et al. (2014). CD4+CD25hiCD127low Regulatory T Cells Are Increased in Oral Squamous Cell Carcinoma Patients. PloS one 9, e103975. doi:10.1371/ journal.pone.0103975

Liu, T.-Y., Chung, Y.-T., Wang, P.-F., Chi, C.-W., and Hsieh, L.-L. (2004). SafroleDNA Adducts in Human Peripheral Blood-An Association with Areca Quid Chewing and CYP2E1 Polymorphisms. Mutat. Research/Genetic Toxicol. Environ. Mutagenesis 559, 59-66. doi:10.1016/j.mrgentox.2003.12.013

Liu, X., Zhang, Y., Cheng, C., Cheng, A. W., Zhang, X., Li, N., et al. (2017). CRISPRCas9-mediated Multiplex Gene Editing in CAR-T Cells. Cell Res 27, 154-157. doi:10.1038/cr.2016.142

Mahanonda, R., Sa-Ard-Iam, N., Eksomtramate, M., Rerkyen, P., Phairat, B., Schaecher, K. E., et al. (2009). Cigarette Smoke Extract Modulates Human $\beta$-defensin-2 and Interleukin-8 Expression in Human Gingival Epithelial Cells. J. Periodontal Res. 44, 557-564. doi:10.1111/j.1600-0765.2008.01153.x

Mayes, P. A., Hance, K. W., and Hoos, A. (2018). The Promise and Challenges of Immune Agonist Antibody Development in Cancer. Nat. Rev. Drug Discov. 17, 509-527. doi:10.1038/nrd.2018.75

Meuric, V., Le Gall-David, S., Boyer, E., Acuna-Amador, L., Martin, B., Fong, S. B., et al. (2017). Signature of Microbial Dysbiosis in Periodontitis. Appl. Environ. Microbiol. 83. doi:10.1128/aem.00462-17

Mio, T., Romberger, D. J., Thompson, A. B., Robbins, R. A., Heires, A., and Rennard, S. I. (1997). Cigarette Smoke Induces Interleukin-8 Release from Human Bronchial Epithelial Cells. Am. J. Respir. Crit. Care Med. 155, 1770-1776. doi:10.1164/ajrccm.155.5.9154890

Misra, C., Majumder, M., Bajaj, S., Ghosh, S., Roy, B., and Roychoudhury, S. (2009). Polymorphisms Atp53,p73, andMDM2loci Modulate the Risk of Tobacco Associated Leukoplakia and Oral Cancer. Mol. Carcinog. 48, 790-800. doi:10.1002/mc.20523

Mocellin, S., Marincola, F., Riccardo Rossi, C., Nitti, D., and Lise, M. (2004). The Multifaceted Relationship between IL-10 and Adaptive Immunity: Putting Together the Pieces of a Puzzle. Cytokine Growth Factor. Rev. 15, 61-76. doi:10.1016/j.cytogfr.2003.11.001

Monasterio, G., Fernández, B., Castillo, F., Rojas, C., Cafferata, E. A., Rojas, L., et al. (2019). Capsular-defectivePorphyromonas Gingivalismutant Strains Induce Less Alveolar Bone Resorption Than W50 Wild-type Strain Due to a Decreased Th1/Th17 Immune Response and Less Osteoclast Activity. J. Periodontol. 90, 522-534. doi:10.1002/jper.18-0079

Morgan, M. J., and Liu, Z.-g. (2011). Crosstalk of Reactive Oxygen Species and NFKb Signaling. Cel Res 21, 103-115. doi:10.1038/cr.2010.178

Mortaz, E., Lazar, Z., Koenderman, L., Kraneveld, A. D., Nijkamp, F. P., and Folkerts, G. (2009). Cigarette Smoke Attenuates the Production of Cytokines by Human Plasmacytoid Dendritic Cells and Enhances the Release of IL-8 in Response to TLR-9 Stimulation. Respir. Res. 10, 47. doi:10.1186/1465-992110-47

Mota, F., Rayment, N., Chong, S., Singer, A., and Chain, B. (1999). The AntigenPresenting Environment in normal and Human Papillomavirus (HPV)-related Premalignant Cervical Epithelium. Clin. Exp. Immunol. 116, 33-40. doi:10.1046/j.1365-2249.1999.00826.x

Mroz, E. A., Patel, K. B., and Rocco, J. W. (2020). Intratumor Heterogeneity Could Inform the Use and Type of Postoperative Adjuvant Therapy in Patients with 
Head and Neck Squamous Cell Carcinoma. Cancer 126, 1895-1904. doi:10.1002/cncr.32742

Murray, P. J., and Wynn, T. A. (2011). Protective and Pathogenic Functions of Macrophage Subsets. Nat. Rev. Immunol. 11, 723-737. doi:10.1038/nri3073

Nagarsheth, N., Wicha, M. S., and Zou, W. (2017). Chemokines in the Cancer Microenvironment and Their Relevance in Cancer Immunotherapy. Nat. Rev. Immunol. 17, 559-572. doi:10.1038/nri.2017.49

Ng, S. K. C., Kabat, G. C., and Wynder, E. L. (1993). Oral Cavity Cancer in Nonusers of Tobacco. JNCI J. Natl. Cancer Inst. 85, 743-745. doi:10.1093/jnci/ 85.9.743

Niedbala, W., Wei, X.-q., Cai, B., Hueber, A. J., Leung, B. P., McInnes, I. B., et al. (2007). IL-35 Is a Novel Cytokine with Therapeutic Effects against CollagenInduced Arthritis through the Expansion of Regulatory T Cells and Suppression of Th17 Cells. Eur. J. Immunol. 37, 3021-3029. doi:10.1002/eji.200737810

Nishimura, T., Iwakabe, K., Sekimoto, M., Ohmi, Y., Yahata, T., Nakui, M., et al. (1999). Distinct Role of Antigen-specific T Helper Type 1 (Th1) and Th2 Cells in Tumor Eradication In Vivo. J. Exp. Med. 190, 617-628. doi:10.1084/ jem.190.5.617

Numasaki, M., Watanabe, M., Suzuki, T., Takahashi, H., Nakamura, A., McAllister, F., et al. (2005). IL-17 Enhances the Net Angiogenic Activity and In Vivo Growth of Human Non-small Cell Lung Cancer in SCID Mice through Promoting CXCR-2-dependent Angiogenesis. J. Immunol. 175, 6177-6189. doi:10.4049/jimmunol.175.9.6177

Nuorti, J. P., Butler, J. C., Farley, M. M., Harrison, L. H., McGeer, A., Kolczak, M. S., et al. (2000). Cigarette Smoking and Invasive Pneumococcal Disease. N. Engl. J. Med. 342, 681-689. doi:10.1056/nejm200003093421002

Okkenhaug, K. (2013). Signaling by the Phosphoinositide 3-Kinase Family in Immune Cells. Аnпu. Rev. Immunol. 31, 675-704. doi:10.1146/annurevimmunol-032712-095946

Okubo, M., Kioi, M., Nakashima, H., Sugiura, K., Mitsudo, K., Aoki, I., et al. (2016). M2-polarized Macrophages Contribute to Neovasculogenesis, Leading to Relapse of Oral Cancer Following Radiation. Scientific Rep. 6, 27548. doi:10.1038/srep27548

Padrao, E., Oliveira, O., Felgueiras, O., Gaio, A. R., and Duarte, R. (2018). Tuberculosis and Tobacco: Is There Any Epidemiological Association? Eur. Respir. J. 51, 1702121. doi:10.1183/13993003.02121-2017

Pan, H.-n., Sun, R., Jaruga, B., Hong, F., Kim, W.-H., and Gao, B. (2006). Chronic Ethanol Consumption Inhibits Hepatic Natural Killer Cell Activity and Accelerates Murine Cytomegalovirus-Induced Hepatitis. Alcohol. Clin. Exp. Res. 30, 1615-1623. doi:10.1111/j.1530-0277.2006.00194.x

Park, J., Wysocki, R. W., Amoozgar, Z., Maiorino, L., Fein, M. R., Jorns, J., et al. (2016). Cancer Cells Induce Metastasis-Supporting Neutrophil Extracellular DNA Traps. Sci. translational Med. 8, 361ra138. doi:10.1126/scitranslmed.aag1711

Parker, B. S., Rautela, J., and Hertzog, P. J. (2016). Antitumour Actions of Interferons: Implications for Cancer Therapy. Nat. Rev. Cancer 16, 131-144. doi:10.1038/nrc.2016.14

Pérez-Sayáns, M., Somoza-Martín, J. M., Barros-Angueira, F., Reboiras-López, M. D., Gándara Rey, J. M., and García-García, A. (2009). Genetic and Molecular Alterations Associated with Oral Squamous Cell Cancer (Review). Oncol. Rep. 22, 1277-1282. doi:10.3892/or_00000565

Phillips, D. H. (2002). Smoking-related DNA and Protein Adducts in Human Tissues. Carcinogenesis 23, 1979-2004. doi:10.1093/carcin/23.12.1979

Piersma, S. J. (2011). Immunosuppressive Tumor Microenvironment in Cervical Cancer Patients. Cancer Microenvironment 4, 361-375. doi:10.1007/s12307011-0066-7

Qin, Z., and Blankenstein, T. (2000). CD4 + T Cell-Mediated Tumor Rejection Involves Inhibition of Angiogenesis that Is Dependent on IFN $\gamma$ Receptor Expression by Nonhematopoietic Cells. Immunity 12, 677-686. doi:10.1016/ s1074-7613(00)80218-6

Quan, H., Shan, Z., Liu, Z., Liu, S., Yang, L., Fang, X., et al. (2020). The Repertoire of Tumor-Infiltrating Lymphocytes within the Microenvironment of Oral Squamous Cell Carcinoma Reveals Immune Dysfunction. Cancer Immunol. Immunother. 69, 465-476. doi:10.1007/s00262-020-02479-x

Rahman, S., Kraljevic Pavelic, S., and Markova-Car, E. (2019). Circadian (De) regulation in Head and Neck Squamous Cell Carcinoma. Int. J. Mol. Sci. 20. doi:10.3390/ijms20112662

Razavi, S. M., Tahani, B., Nouri, S., and Khazaei, A. (2015). Oral Cancer Knowledge and Practice Among Dental Patients and Their Attitude towards Tobacco
Cessation in Iran. Asian Pac. J. Cancer Prev. 16, 5439-5444. doi:10.7314/ apjcp.2015.16.13.5439

Rehman, S., Chandel, N., Salhan, D., Rai, P., Sharma, B., Singh, T., et al. (2013). Ethanol and Vitamin D Receptor in T Cell Apoptosis. J. Neuroimmune Pharmacol. 8, 251-261. doi:10.1007/s11481-012-9393-9

Remani, P., Ankathil, R., Vijayan, K. K., Haseena Beevi, V. M., Rajendran, R., and Vijayakumar, T. (1988). Circulating Immune Complexes as an Immunological Marker in Premalignant and Malignant Lesions of the Oral Cavity. Cancer Lett. 40, 185-191. doi:10.1016/0304-3835(88)90009-2

Romero, D. (2016). Immunotherapy: PD-1 Says Goodbye, TIM-3 Says Hello, Nature Reviews. Clin. Oncol. 13, 202-203. doi:10.1038/nrclinonc.2016.40

Rowshanravan, B., Halliday, N., and Sansom, D. M. (2018). CTLA-4: a Moving Target in Immunotherapy. Blood 131, 58-67. doi:10.1182/blood-2017-06741033

Sahibzada, H. A., Khurshid, Z., Khan, R. S., Naseem, M., Siddique, K. M., Mali, M., et al. (2017). Salivary IL-8, IL-6 and TNF- $\alpha$ as Potential Diagnostic Biomarkers for Oral Cancer. Diagnostics (Basel) 7, 21. doi:10.3390/diagnostics7020021

Sakaguchi, S. (2004). NaturallyArisingCD4+RegulatoryT Cells forImmunologicSelf-Tolerance andNegativeControl oflmmuneResponses. $\begin{array}{llll}\text { Annu. Rev. Immunol. 22, 531-562. doi:10.1146/ } & \end{array}$ annurev.immunol.21.120601.141122

Sankaranarayanan, R., Mathew, B., Varghese, C., Sudhakaran, P., Menon, V., Jayadeep, A., et al. (1997). Chemoprevention of Oral Leukoplakia with Vitamin A and Beta Carotene: an Assessment. Oral Oncol. 33, 231-236. doi:10.1016/ s0964-1955(97)00010-9

Sato-Kaneko, F., Yao, S., Ahmadi, A., Zhang, S. S., Hosoya, T., Kaneda, M. M., et al. (2017). Combination Immunotherapy with TLR Agonists and Checkpoint Inhibitors Suppresses Head and Neck Cancer. JCI Insight 2. doi:10.1172/ jci.insight. 93397

Schubert, A. D., Channah Broner, E., Agrawal, N., London, N., Pearson, A., Gupta, A., et al. (2020). Somatic Mitochondrial Mutation Discovery Using Ultra-deep Sequencing of the Mitochondrial Genome Reveals Spatial Tumor Heterogeneity in Head and Neck Squamous Cell Carcinoma. Cancer Lett. 471, 49-60. doi:10.1016/j.canlet.2019.12.006

Schwarz, S., Butz, M., Morsczeck, C., Reichert, T. E., and Driemel, O. (2008). Increased Number of CD25+ FoxP3+ Regulatory T Cells in Oral Squamous Cell Carcinomas Detected by Chromogenic Immunohistochemical Double Staining. official Publ. Int. Assoc. Oral Pathol. Am. Acad. Oral Pathol. 37, 485-489. doi:10.1111/j.1600-0714.2008.00641.x

Selvan, R. S., Selvakumaran, M., and Rao, A. R. (1991). Influence of Arecoline on Immune System: II. Suppression of Thymus-dependent Immune Responses and Parameter of Non-specific Resistance after Short-Term Exposure. Immunopharmacology and Immunotoxicology 13, 281-309. doi:10.3109/ 08923979109019706

Sethi, G., Sung, B., and Aggarwal, B. B. (2008). TNF: A Master Switch for Inflammation to Cancer. Front. Biosci. Volume, 5094-5107. doi:10.2741/3066

Shang, B., Liu, Y., Jiang, S. J., and Liu, Y. (2015). Prognostic Value of TumorInfiltrating FoxP3+ Regulatory T Cells in Cancers: a Systematic Review and Meta-Analysis. Scientific Rep. 5, 15179. doi:10.1038/srep15179

Shimizu, S., Hiratsuka, H., Koike, K., Tsuchihashi, K., Sonoda, T., Ogi, K., et al. (2019). Tumor-infiltrating CD8+ T-Cell Density Is an Independent Prognostic Marker for Oral Squamous Cell Carcinoma. Cancer Med. 8, 80-93. doi:10.1002/ cam4.1889

Shojaei, F., Wu, X., Qu, X., Kowanetz, M., Yu, L., Tan, M., et al. (2009). G-CSFinitiated Myeloid Cell Mobilization and Angiogenesis Mediate Tumor Refractoriness to Anti-VEGF Therapy in Mouse Models. Proc. Natl. Acad. Sci. 106, 6742-6747. doi:10.1073/pnas.0902280106

Singh, P. K., Kumar, V., Ahmad, M. K., Gupta, R., Mahdi, A. A., Jain, A., et al. (2017). Association of -330 Interleukin-2 Gene Polymorphism with Oral Cancer. Indian J. Med. Res. 146, 730-737. doi:10.4103/ijmr.IJMR_1949_15

Smigiel, K. S., Srivastava, S., Stolley, J. M., and Campbell, D. J. (2014). Regulatory T-Cell Homeostasis: Steady-State Maintenance and Modulation during Inflammation. Immunol. Rev. 259, 40-59. doi:10.1111/imr.12170

Solomon, B. L., and Garrido-Laguna, I. (2018). TIGIT: a Novel Immunotherapy Target Moving from Bench to Bedside. Cancer Immunol. Immunother. 67, 1659-1667. doi:10.1007/s00262-018-2246-5

Solomon, B., Young, R. J., and Rischin, D. (2018). Head and Neck Squamous Cell Carcinoma: Genomics and Emerging Biomarkers for Immunomodulatory 
Cancer Treatments. Semin. Cancer Biol. 52, 228-240. doi:10.1016/ j.semcancer.2018.01.008

Spitzer, J. H., and Meadows, G. G. (1999). Modulation of Perforin, Granzyme A, and Granzyme B in Murine Natural Killer (NK), IL2 Stimulated NK, and Lymphokine-Activated Killer Cells by Alcohol Consumption. Cell Immunol. 194, 205-212. doi:10.1006/cimm.1999.1511

Spolski, R., Li, P., and Leonard, W. J. (2018). Biology and Regulation of IL-2: from Molecular Mechanisms to Human Therapy. Nat. Rev. Immunol. 18, 648-659. doi:10.1038/s41577-018-0046-y

Stasikowska-Kanicka, O., Wągrowska-Danilewicz, M., and Danilewicz, M. (2018). CD8+ and CD163+ Infiltrating Cells and PD-L1 Immunoexpression in Oral Leukoplakia and Oral Carcinoma. Apmis 126, 732-738. doi:10.1111/apm.12881

Stasikowska-Kanicka, O., Wągrowska-Danilewicz, M., and Danilewicz, M. (2018). Immunohistochemical Analysis of Foxp3+, CD4+, CD8+ Cell Infiltrates and PD-L1 in Oral Squamous Cell Carcinoma. Pathol. Oncol. Res. 24, 497-505. doi:10.1007/s12253-017-0270-y

Støy, S., Dige, A., Sandahl, T. D., Laursen, T. L., Buus, C., Hokland, M., et al. (2015). Cytotoxic T Lymphocytes and Natural Killer Cells Display Impaired Cytotoxic Functions and Reduced Activation in Patients with Alcoholic Hepatitis. Am. J. Physiol. Gastrointest. Liver Physiol. 308, G269-G276. doi:10.1152/ ajpgi.00200.2014

Strachan, D. C., Ruffell, B., Oei, Y., Bissell, M. J., Coussens, L. M., Pryer, N., et al. (2013). CSF1R Inhibition Delays Cervical and Mammary Tumor Growth in Murine Models by Attenuating the Turnover of Tumor-Associated Macrophages and Enhancing Infiltration by CD8(+) $\mathrm{T}$ Cells. Oncoimmunology 2, e26968. doi:10.4161/onci.26968

Su, L., Xu, Q., Zhang, P., Michalek, S. M., and Katz, J. (2017). Phenotype and Function of Myeloid-Derived Suppressor Cells Induced by Porphyromonas Gingivalis Infection. Infect. Immun. 85, e00213-17. doi:10.1128/iai.00213-17

Suwa, T., Saio, M., Umemura, N., Yamashita, T., Toida, M., Shibata, T., et al. (2006). Preoperative Radiotherapy Contributes to Induction of Proliferative Activity of CD8+ Tumor-Infiltrating T-Cells in Oral Squamous Cell Carcinoma. Oncol. Rep. 15, 757-763. doi:10.3892/or.15.4.757

Tang, M., Diao, J., and Cattral, M. S. (2017). Molecular Mechanisms Involved in Dendritic Cell Dysfunction in Cancer. Cell. Mol. Life Sci. 74, 761-776. doi:10.1007/s00018-016-2317-8

Tatsumi, T., Kierstead, L. S., Ranieri, E., Gesualdo, L., Schena, F. P., Finke, J. H., et al. (2002). Disease-associated Bias in T Helper Type 1 (Th1)/Th2 CD4+ T Cell Responses against MAGE-6 in HLA-Drb1 ${ }^{\star} 0401+$ Patients with Renal Cell Carcinoma or Melanoma. J. Exp. Med. 196, 619-628. doi:10.1084/ jem.20012142

Tepper, R. I., Pattengale, P. K., and Leder, P. (1989). Murine Interleukin-4 Displays Potent Anti-tumor Activity In Vivo. Cell 57, 503-512. doi:10.1016/00928674(89)90925-2

Tosolini, M., Kirilovsky, A., Mlecnik, B., Fredriksen, T., Mauger, S., Bindea, G., et al. (2011). Clinical Impact of Different Classes of Infiltrating T Cytotoxic and Helper Cells (Th1, Th2, Treg, Th17) in Patients with Colorectal Cancer. Cancer Res. 71, 1263-1271. doi:10.1158/0008-5472.can-10-2907

Trinchieri, G. (2003). Interleukin-12 and the Regulation of Innate Resistance and Adaptive Immunity. Nat. Rev. Immunol. 3, 133-146. doi:10.1038/nri1001

Tsukamoto, H., Fujieda, K., Miyashita, A., Fukushima, S., Ikeda, T., Kubo, Y., et al. (2018). Combined Blockade of IL6 and PD-1/pd-L1 Signaling Abrogates Mutual Regulation of Their Immunosuppressive Effects in the Tumor Microenvironment. Cancer Res. 78, 5011-5022. doi:10.1158/0008-5472.can18-0118

Tsunoda, K., Tsujino, I., Koshi, R., Sugano, N., Sato, S., and Asano, M. (2016). Nicotine-Mediated Ca 2+-Influx Induces IL-8 Secretion in Oral Squamous Cell Carcinoma Cell. J. Cel. Biochem. 117, 1009-1015. doi:10.1002/jcb.25387

Türkseven, M. R., and Oygür, T. (2010). Evaluation of Natural Killer Cell Defense in Oral Squamous Cell Carcinoma. Oral Oncol. 46, e34-e37. doi:10.1016/ j.oraloncology.2010.02.019

Utispan, K., Pugdee, K., and Koontongkaew, S. (2018). Porphyromonas Gingivalis Lipopolysaccharide-Induced Macrophages Modulate Proliferation and Invasion of Head and Neck Cancer Cell Lines. Biomed. Pharmacother. 101, 988-995. doi:10.1016/j.biopha.2018.03.033

van Schalkwyk, M. C. I., Papa, S. E., Jeannon, J.-P., Urbano, T. G., Spicer, J. F., and Maher, J. (2013). Design of a Phase I Clinical Trial to Evaluate Intratumoral Delivery of ErbB-Targeted Chimeric Antigen Receptor T-Cells in Locally
Advanced or Recurrent Head and Neck Cancer. Hum. Gene Ther. Clin. Develop. 24, 134-142. doi:10.1089/humc.2013.144

Vassallo, R., Kroening, P. R., Parambil, J., and Kita, H. (2008). Nicotine and Oxidative Cigarette Smoke Constituents Induce Immune-Modulatory and Proinflammatory Dendritic Cell Responses. Mol. Immunol. 45, 3321-3329. doi:10.1016/j.molimm.2008.04.014

Vassallo, R., Tamada, K., Lau, J. S., Kroening, P. R., and Chen, L. (2005). Cigarette Smoke Extract Suppresses Human Dendritic Cell Function Leading to Preferential Induction of Th-2 Priming. J. Immunol. 175, 2684-2691. doi:10.4049/jimmunol.175.4.2684

Vassallo, R., Tamada, K., Lau, J. S., Kroening, P. R., and Chen, L. (2005). Cigarette Smoke Extract Suppresses Human Dendritic Cell Function Leading to Preferential Induction of Th-2 Priming. J. Immunol. 175, 2684-2691. doi:10.4049/jimmunol.175.4.2684

Verma, A., Vincent-Chong, V. K., DeJong, H., Hershberger, P. A., and Seshadri, M. (2020). Impact of Dietary Vitamin D on Initiation and Progression of Oral Cancer. J. Steroid Biochem. Mol. Biol. 199, 105603. doi:10.1016/ j.jsbmb.2020.105603

Vonderheide, R. H. (2020). CD40 Agonist Antibodies in Cancer Immunotherapy. Annu. Rev. Med. 71, 47-58. doi:10.1146/annurev-med-062518-045435

Wang, C.-C., Chen, T.-Y., Wu, H.-Y., Liu, T.-Y., and Jan, T.-R. (2012). Areca Nut Extracts Suppress the Differentiation and Functionality of Human MonocyteDerived Dendritic Cells. J. Periodont Res. 47, 198-203. doi:10.1111/j.16000765.2011.01421.x

Wang, C. C., Liu, T. Y., Wey, S. P., Wang, F. I., and Jan, T. R. (2007). Areca Nut Extract Suppresses T-Cell Activation and Interferon- $\gamma$ Production via the Induction of Oxidative Stress. Food Chem. Toxicol. 45, 1410-1418. doi:10.1016/j.fct.2007.02.005

Wang, C., Ye, Y., Hochu, G. M., Sadeghifar, H., and Gu, Z. (2016). Enhanced Cancer Immunotherapy by Microneedle Patch-Assisted Delivery of Anti-PD1 Antibody. Nano Lett. 16, 2334-2340. doi:10.1021/acs.nanolett.5b05030

Wang, H., Liang, X., Li, M., Tao, X., Tai, S., Fan, Z., et al. (2017). Chemokine (CCmotif) Ligand 18 Upregulates Slug Expression to Promote Stem-cell like Features by Activating the Mammalian Target of Rapamycin Pathway in Oral Squamous Cell Carcinoma. Cancer Sci. 108, 1584-1593. doi:10.1111/cas.13289

Wang, Z., and Cao, Y. J. (2020). Adoptive Cell Therapy Targeting Neoantigens: A Frontier for Cancer Research,. Front. Immunol. 11, 176. doi:10.3389/ fimmu.2020.00176

Wang, Z., Wu, V. H., Allevato, M. M., Gilardi, M., He, Y., Luis Callejas-Valera, J., et al. (2019). Syngeneic Animal Models of Tobacco-Associated Oral Cancer Reveal the Activity of In Situ Anti-CTLA-4. Nat. Commun. 10, 5546. doi:10.1038/s41467-019-13471-0

Weng, C.-J., Chien, M.-H., Lin, C.-W., Chung, T.-T., Zavras, A.-I., Tsai, C.-M., et al. (2010). Effect of CC Chemokine Ligand 5 and CC Chemokine Receptor 5 Genes Polymorphisms on the Risk and Clinicopathological Development of Oral Cancer. Oral Oncol. 46, 767-772. doi:10.1016/j.oraloncology.2010.07.011

Wu, J., Peters, B. A., Dominianni, C., Zhang, Y., Pei, Z., Yang, L., et al. (2016). Cigarette Smoking and the Oral Microbiome in a Large Study of American Adults. Isme J. 10, 2435-2446. doi:10.1038/ismej.2016.37

Wu, W.-S. (2006). The Signaling Mechanism of ROS in Tumor Progression. Cancer Metastasis Rev. 25, 695-705. doi:10.1007/s10555-006-9037-8

Wu, W. J., Wolcott, R. M., and Pruett, S. B. (1994). Ethanol Decreases the Number and Activity of Splenic Natural Killer Cells in a Mouse Model for Binge Drinking. J. Pharmacol. Exp. Ther. 271, 722-729.

Wustrow, T. P., and Mahnke, C. G. (1996). Causes of Immunosuppression in Squamous Cell Carcinoma of the Head and Neck. Anticancer Res. 16, 2433-2468.

Xia, L., Liu, Y., and Wang, Y. (2019). PD-1/PD-L1 Blockade Therapy in Advanced Non-Small-Cell Lung Cancer: Current Status and Future Directions. Oncol. 24, S31-s41. doi:10.1634/theoncologist.2019-io-s1-s05

Xiao, M., Zhang, J., Chen, W., and Chen, W. (2018). M1-like Tumor-Associated Macrophages Activated by Exosome-Transferred THBS1 Promote Malignant Migration in Oral Squamous Cell Carcinoma, Journal of Experimental \& Clinical Cancer Research. CR 37, 143. doi:10.1186/s13046-018-0815-2

Xie, C., Ji, N., Tang, Z., Li, J., and Chen, Q. (2019). The Role of Extracellular Vesicles from Different Origin in the Microenvironment of Head and Neck Cancers,. Mol. Cancer 18, 83. doi:10.1186/s12943-019-0985-3

Yakin, M., Gavidi, R. O., Cox, B., and Rich, A. (2017). Oral Cancer Risk Factors in New Zealand. N. Z. Med. J. 130, 30-38. 
Yang, J. A., Huber, S. A., and Lucas, Z. J. (1979). Inhibition of DNA Synthesis in Cultured Lymphocytes and Tumor Cells by Extracts of Betel Nut, Tobacco, and Miang Leaf, Plant Substances Associated with Cancer of the Ororespiratory Epithelium. Cancer Res. 39, 4802-4809.

Yeku, O., Li, X., and Brentjens, R. J. (2017). Adoptive T-Cell Therapy for Solid Tumors. Am. Soc. Clin. Oncol. Educ. Book 37, 193-204. doi:10.1200/edbk_180328

Yi, H.-S., Lee, Y.-S., Byun, J.-S., Seo, W., Jeong, J.-M., Park, O., et al. (2014). Alcohol Dehydrogenase III Exacerbates Liver Fibrosis by Enhancing Stellate Cell Activation and Suppressing Natural Killer Cells in Mice. Hepatology 60, 1044-1053. doi:10.1002/hep.27137

Yu, G., Phillips, S., Gail, M. H., Goedert, J. J., Humphrys, M. S., Ravel, J., et al. (2017). The Effect of Cigarette Smoking on the Oral and Nasal Microbiota,. Microbiome 5, 3. doi:10.1186/s40168-016-0226-6

Zhang, F., Little, A., and Zhang, H. (2017). Chronic Alcohol Consumption Inhibits Peripheral NK Cell Development and Maturation by Decreasing the Availability of IL-15. J. Leukoc. Biol. 101, 1015-1027. doi:10.1189/jlb.1a0716-298rr

Zhang, H., and Meadows, G. G. (2010). Chronic Alcohol Consumption Enhances Myeloid-Derived Suppressor Cells in B16BL6 Melanoma-Bearing Mice. Cancer Immunol. Immunother. 59, 1151-1159. doi:10.1007/s00262-010-0837-x

Zhang, H., and Meadows, G. G. (2008). Chronic Alcohol Consumption Perturbs the Balance between Thymus-Derived and Bone Marrow-Derived Natural Killer Cells in the Spleen. J. Leukoc. Biol. 83, 41-47. doi:10.1189/jlb.0707472

Zhang, H., and Meadows, G. G. (2009). Exogenous IL-15 in Combination with IL15Ra Rescues Natural Killer Cells from Apoptosis Induced by Chronic Alcohol Consumption. Clin. Exp. Res. 33, 419-427. doi:10.1111/j.15300277.2008.00852.x

Zhang, H., Zhu, Z., and Meadows, G. G. (2011). Chronic Alcohol Consumption Decreases the Percentage and Number of NK Cells in the Peripheral Lymph Nodes and Exacerbates B16BL6 Melanoma Metastasis into the Draining Lymph Nodes. Cell Immunol. 266, 172-179. doi:10.1016/j.cellimm.2010.10.001

Zhang, Q., Bi, J., Zheng, X., Chen, Y., Wang, H., Wu, W., et al. (2018). Blockade of the Checkpoint Receptor TIGIT Prevents NK Cell Exhaustion and Elicits Potent Anti-tumor Immunity. Nat. Immunol. 19, 723-732. doi:10.1038/ s41590-018-0132-0
Zhang, Q., Qin, J., Zhong, L., Gong, L., Zhang, B., Zhang, Y., et al. (2015). CCL5Mediated Th2 Immune Polarization Promotes Metastasis in Luminal Breast Cancer. Cancer Res. 75, 4312-4321. doi:10.1158/0008-5472.can-14-3590

Zhao, J., Chen, X., Herjan, T., and Li, X. (2020). The Role of Interleukin-17 in Tumor Development and Progression,. J. Exp. Med. 217. doi:10.1084/ jem.20190297

Zhou, J., and Meadows, G. G. (2003). Alcohol Consumption Decreases IL-2Induced NF-kappaB Activity in Enriched NK Cells from C57BL/6 Mice. official J. Soc. Toxicol. 73, 72-79. doi:10.1093/toxsci/kfg047

Zhu, C., Kros, J. M., Cheng, C., and Mustafa, D. (2017). The Contribution of Tumor-Associated Macrophages in Glioma Neo-Angiogenesis and Implications for Anti-angiogenic Strategies. Neuro-oncology 19, 1435-1446. doi:10.1093/neuonc/nox081

Zou, J.-M., Qin, J., Li, Y.-C., Wang, Y., Li, D., Shu, Y., et al. (2017). IL-35 Induces N2 Phenotype of Neutrophils to Promote Tumor Growth. Oncotarget 8, 33501-33514. doi:10.18632/oncotarget.16819

Conflict of Interest: The authors declare that the research was conducted in the absence of any commercial or financial relationships that could be construed as a potential conflict of interest.

Publisher's Note: All claims expressed in this article are solely those of the authors and do not necessarily represent those of their affiliated organizations, or those of the publisher, the editors, and the reviewers. Any product that may be evaluated in this article, or claim that may be made by its manufacturer, is not guaranteed or endorsed by the publisher.

Copyright (c) 2021 Sun, Tang, Zhang, Chen, Peng and Chen. This is an open-access article distributed under the terms of the Creative Commons Attribution License (CC $B Y)$. The use, distribution or reproduction in other forums is permitted, provided the original author(s) and the copyright owner(s) are credited and that the original publication in this journal is cited, in accordance with accepted academic practice. No use, distribution or reproduction is permitted which does not comply with these terms. 